\title{
Influence of the nature of interfaces on the capillary transport in layered materials
}

\author{
Hannelore Derluyn ${ }^{1,2,3}$, Hans Janssen ${ }^{4}$ and Jan Carmeliet ${ }^{2,3}$ \\ ${ }^{1}$ Laboratory of Building Physics, Department of Civil Engineering, \\ Katholieke Universiteit Leuven (KUL), Kasteelpark Arenberg 40, 3001 Leuven, Belgium \\ ${ }^{2}$ Chair of Building Physics, ETH Zürich, \\ Wolfgang-Pauli-Str. 15, 8093 Zürich, Switzerland, \\ derluyn@arch.ethz.ch; carmeliet@arch.ethz.ch \\ ${ }^{3}$ Laboratory for Building Science and Technology, \\ EMPA, Swiss Federal Laboratories for Materials Science and Technology, \\ Überlandstrasse 129, 8600 Dübendorf, Switzerland, \\ hannelore.derluyn@empa.ch; jan.carmliet@empa.ch \\ ${ }^{4}$ Department of Civil Engineering, Technical University of Denmark (DTU), \\ Brovej - Building 118, 2800 Kgs. Lyngby, Denmark, \\ haj@byg.dtu.dk
}

\begin{abstract}
This paper presents an experimental and quantitative analysis of capillary transport across the interface brick-mortar joint in masonry. Moisture profiles are measured with X-ray projection. The influence of curing conditions is analyzed by considering three types of mortars: cured in a mould, between capillary wet and dry bricks. A decrease in moisture inflow for the mortars cured between bricks is measured. The pore structure and the moisture transport properties of mortar change significantly due to water extraction from the initially wet mortar to the bricks during curing. Numerical simulations reveal the existence of a hydraulic interface resistance between brick and wet/dry cured mortar.
\end{abstract}

\section{Keywords}

moisture transport; masonry; mortar; curing; hygric properties; interface resistance

\section{Introduction}

In large parts of the world, building envelopes are made of masonry. These walls are exposed to driving rain, night condensation and occasionally to rising damp. Wetting and drying of the masonry may result in moisture damage, such as algae and moss growth, staining due to salt efflorescence, or cracking and spalling due to freeze-thaw cycles or crystallization of salts. To assess the durability or prevent damage to masonry constructions, a detailed understanding of the capillary transport in masonry is required.

Capillary transport in homogeneous materials is generally described by continuum theory [1], for which moisture transport properties are determined using standardized or more advanced methods and for which validated heat and mass transport models are on hand [2-8]. Capillary transport in masonry, a multi-layered material composed of bricks and mortar joints, deviates from the classical capillary transport in a homogeneous material. In literature, the deviation is attributed to the presence of a hydraulic resistance at the brick-mortar interface [9-11] or to a change of the moisture transport properties of the mortar joint [12]. The change in moisture transport properties of mortar is explained by the curing conditions of the fresh mortar. The fresh mortar is placed between two bricks and extraction of water from the fresh mortar to the 
Postprint: Derluyn H, Janssen H, Carmeliet J, 2011. Influence of the nature of interfaces on the capillary transport in layered materials, Construction and Building Materials, 25: 3685-3693.

doi:10.1016/j.conbuildmat.2011.03.063

brick may result in a change of the water/cement factor and resulting properties of the mortar [10, 12-14]. Nyame and Illston [15] and Goto and Roy [16] show that porosity decreases with decreasing water-cement ratio for hardened cement paste. This conclusion holds up to the point when water becomes insufficient to properly hydrate the cement components. Sanjuán and Muñoz-Marialay [17] found for concrete a linear increase of the air permeability coefficient with the water-cement ratio.

The objectives of this paper are: (1) to get detailed experimental information on the capillary transport across the brick-mortar interface in masonry; (2) to accurately measure the change of moisture transport properties of mortar depending on the curing conditions; (3) to simulate and explain the imperfect hydraulic contact at the brick-mortar interface.

In section 2, X-ray measurements of the capillary water uptake in brick-mortar specimens with different curing conditions for the mortar are analyzed. In section 3, the simulations of the experiments and the experimental determination of the moisture transport properties for the different materials are presented. In section 4, we discuss the findings and present the determination of the extraction of water from the fresh mortar to the brick during curing and the microscopic analysis of the brick-mortar interface. Eventually, the conclusions are given in section 5 .

\section{X-ray measurements of capillary uptake in masonry}

\subsection{Masonry test samples}

Masonry samples with three different types of mortar joint are considered:

1. Perfect contact samples consisting of brick - kaolin layer - mould cured mortar - kaolin layer - brick;

2. Wet cured samples. These samples are made by joining capillary saturated bricks with fresh mortar and the mortar is cured between the capillary saturated bricks;

3. Dry cured samples. These samples are made by joining oven dry bricks with fresh mortar and the mortar is cured between the oven dry bricks.

In case 1 a layer of kaolin clay is applied between the different materials to assure a perfect hydraulic contact. Cases 2 and 3 represent limit cases of academic interest. In building practice bricks may show an initial moisture content in between those limits: capillary saturated and oven dry brick.

A standardized cement mortar is used, obtained by mixing six weight parts of river sand, two parts of P42.5 Portland cement and one part of tap water. The resulting water-cement factor is 0.5 . For the specimens of case 1 , fresh mortar is poured in moulds and cured for 24 hours under damp cloth. Afterwards, the moulds are removed and the mortar is moved to a curing chamber at $80 \% \mathrm{RH}$ and $20^{\circ} \mathrm{C}$. Red fired clay bricks are cut lengthwise in two halves, having a thickness of approximately $30 \mathrm{~mm}$. For the cases 2 and 3, fresh mortar is applied on the sawed surface with an intended thickness of $10 \mathrm{~mm}$. The second half of the brick is positioned on top, and slightly pressed into the mortar. The samples are cured for 24 hours under damp cloth, and then moved to the curing chamber. After 28 days of curing, $10 \mathrm{~mm}$ is cut from the masonry samples in order to avoid boundary effects. Appropriately sized samples for the mould mortar are obtained by further sawing. The bricks and mould mortar for case 1 and the masonry samples for case 2 and 3 are dried at $50{ }^{\circ} \mathrm{C}$ and $3 \% \mathrm{RH}$. Low temperature drying was chosen to avoid damage during drying and to avoid removing chemically bound water from the cementitious material. After drying, wet kaolin paste is applied on the brick surfaces for case 1 and the mortar is placed in between and slightly pressed to obtain a good contact. The masonry sample is then dried again at $50^{\circ} \mathrm{C}$ and $3 \% \mathrm{RH}$. The average dimensions 
Postprint: Derluyn H, Janssen H, Carmeliet J, 2011. Influence of the nature of interfaces on the capillary transport in layered materials, Construction and Building Materials, 25: 3685-3693.

doi:10.1016/j.conbuildmat.2011.03.063

of the specimens are given in Figure 1. The average width of the samples is $70 \mathrm{~mm}$ and the thickness is $15 \mathrm{~mm}$.

\section{$2.2 X$-ray monitoring of capillary uptake experiments}

In the capillary water uptake experiments, liquid water is applied at the bottom side of the composite brick-mortar-brick. Evaporation at the lateral sides is prevented by using vapor tight foil. The liquid water uptake is perpendicular to the mortar layer and is measured using the X-ray projection method [18]. When an object is irradiated with an X-ray beam, the Xrays attenuate due to the interaction with the material. For quantification of the moisture content field in a porous material, an image during moisture transfer is compared with the image of the dry sample. The difference in X-ray attenuation between the two can then be directly transformed into moisture contents. The study is carried out with a Philips HOMX 161 system and AEA Tomohawk software. The X-ray images are acquired by a 12 bit, $1024 \mathrm{x}$ 1024 pixel CCD camera. Pictures are acquired at a speed of 25 frames/s. In order to reduce noise an averaging of 256 frames is used. The X-ray source is set at $85 \mathrm{keV}$ and $0.30 \mathrm{~mA}$. The resolution in moisture content ranges between 3 to $5 \mathrm{~kg} / \mathrm{m}^{3}$. X-ray projections are taken at defined time steps for all specimens.

\subsection{Results and analysis}

Figure 1 shows, as an example, the result of the X-ray projection method for a masonry specimen after one hour of water uptake (mould cured mortar). The wetting front in the mortar is almost uniform indicating a one-dimensional flow. From these images moisture content profiles are obtained by averaging the X-ray data over a width of $10 \mathrm{~mm}$ in the middle of the specimen.

Figure 2 gives the moisture content profiles in the brick and in the wet cured mortar for a period of 4 hours. A jump in moisture content across the interface from approximately 130 $\mathrm{kg} / \mathrm{m}^{3}$ in brick to $120 \mathrm{~kg} / \mathrm{m}^{3}$ in mortar is observed.

Figures 3a-c give the moisture content profiles in the mortar joint alone for the three cases. The profiles are given for the same time steps. From these figures, we determine the average maximal moisture contents reached in the mortars, also referred to as capillary moisture content $w_{\text {cap }}$. The capillary moisture contents are respectively $130 \mathrm{~kg} / \mathrm{m}^{3}$ for mould mortar, $120 \mathrm{~kg} / \mathrm{m}^{3}$ for wet cured mortar and $100 \mathrm{~kg} / \mathrm{m}^{3}$ for dry cured mortar. We observe that the capillary moisture content $w_{\text {cap }}$ in the mortar depends on the curing conditions and is the lowest for the dry cured mortar. When comparing the moisture content profiles for the different mortars in Figures 3, a fast moisture uptake in the mould mortar is observed. The uptake in the wet cured mortar is slower and slowest in the dry cured mortar. Thus also the moisture uptake rate depends on the curing conditions.

The capillary transport in the mortar is further investigated in more detail. The position of the wetting front $h(t)$ as a function of time $t$ is determined. This position is defined as the position at which the moisture content equals half of the capillary moisture content $w_{\text {cap }}$. Then, assuming that the moisture content profiles can be approximated by sharp fronts [19], the cumulative water inflow in the brick $Q_{B}$, the mortar $Q_{M}$ and the total specimen $Q_{T}$ are determined using the following equations:

$$
\begin{array}{lll}
Q_{B}(t)=h(t) w_{\text {cap }}^{B} & , Q_{M}(t)=0 & , t \leq t_{i} \\
Q_{B}(t)=Q_{B}\left(t_{i}\right) \quad, Q_{M}(t)=\left(h(t)-L_{B}\right) w_{c a p}^{M} & , t \geq t_{i} \\
Q_{T}(t)=Q_{B}(t)+Q_{M}(t) &
\end{array}
$$

with $L_{B}$ the thickness of the brick, $w_{\text {cap }}^{B}$ the capillary moisture content of the brick and $w_{\text {cap }}^{M}$ the capillary moisture content of the mortar. 
Postprint: Derluyn H, Janssen H, Carmeliet J, 2011. Influence of the nature of interfaces on the capillary transport in layered materials, Construction and Building Materials, 25: 3685-3693.

The arrival time $t_{i}$ of the wetting front at the interface brick-mortar is given by:

$t_{i}=\left(\frac{w_{\text {cap }}^{B} L_{B}}{A_{\text {cap }}^{B}}\right)^{2}$

with $A_{\text {cap }}^{B}$ the capillary absorption coefficient of the brick. Figure 4 gives the total cumulative inflow $Q_{T}$ in function of the square root of time. Two parts in the curve can be distinguished. The first part is linear and represents the water uptake in the brick. The uptake curves almost coincide for the three brick specimens. The slope of the curve approximates the capillary absorption coefficient $A_{\text {cap }}^{B}=0.116 \mathrm{~kg} / \mathrm{m}^{2} \mathrm{~s}^{0.5}$. Note that the capillary absorption coefficient of the brick without mortar can differ from the capillary absorption coefficient of the brick with mortar, since the mortar cover may prevent the free outflow of the gas phase at the top side during water uptake. The second part of the curve reflects the uptake by the mortar. Figure 5 gives the inflow curves for the mortar $Q_{M}$ as a square root of time. The small shift in arrival time $t_{i}$ is due to small differences in $L_{B}$ and $A_{\text {cap }}^{B}$ of the brick specimens. The mould mortar shows a nonlinear curve: the inflow process is initially quite fast, followed by a slowing down to an almost linear inflow. For the wet cured mortar, only a short initial period of increased moisture inflow is observed. After this initial period the inflow curve is linear and the slope almost equals the slope for the mould mortar. For the dry cured mortar, no initial period of increased inflow is found. The inflow curve is linear and its slope is lower than the slope for the inflow into mould and wet cured mortar.

To analyze this different behaviour more thoroughly, the inflow rate $g_{i}$ at the interface is determined. Assuming again that the sharp front approximation is valid, the flow rate $g_{i}$ equals - following the principle of mass conservation - the inflow rate at the moving wetting front $g_{m v}$. This rate can be approximated by $g_{i}=g_{m v} \approx \Delta Q / \Delta t$, with $\Delta Q$ the cumulative inflow difference during a time step $\Delta t$. Figure 6 shows the inflow rate versus square root of time. The dashed lines are approximation curves. At the beginning of the uptake process by the mould mortar, a high inflow rate is observed. This inflow rate drops to a constant value after some time. For wet and dry cured mortar, this initial inflow rate is lower. Eventually, also almost constant values are attained. The drop in inflow rate for the mould mortar is logical, since with progressing water front, the hydraulic resistance increases and thus the uptake process slows down. Important to notice is that the initial inflow rate of the wet and dry cured mortar is lower. This can be explained by the presence of an interface resistance and/or due to a change of the moisture transport properties depending on the curing. This observation will be analyzed in the following section.

\section{Numerical simulations}

\subsection{Governing equations}

The isothermal moisture transport for a one-dimensional free water uptake process is described by:

$$
\frac{\partial w}{\partial t}=-C \frac{\partial p_{c}}{\partial t}=-\frac{\partial}{\partial x}\left(K \frac{\partial p_{c}}{\partial x}\right)
$$

with $p_{c}$ the capillary pressure, $w$ the moisture content, $w\left(p_{c}\right)$ the capillary pressure curve, $C\left(p_{c}\right)=\left|\partial w / \partial p_{c}\right|$ the moisture capacity and $K\left(p_{c}\right)$ the unsaturated permeability. The initial condition is:

$0<x<L, \quad t=0 \quad: p_{c}=10^{9} \mathrm{~Pa}$

where $L$ is the total length and a capillary pressure of $10^{9}$ Pa corresponds to a dry material. 
Postprint: Derluyn H, Janssen H, Carmeliet J, 2011. Influence of the nature of interfaces on the capillary transport in layered materials, Construction and Building Materials, 25: 3685-3693.

The boundary conditions are:

$$
\begin{aligned}
& x=0, t>0: p_{c}=10 P a \\
& x=L, t>0: g_{v}=0
\end{aligned}
$$

with $g_{v}$ the vapor flow. The constant capillary pressure at the bottom side $(\mathrm{x}=0)$ of $10 \mathrm{~Pa}$ corresponds to a moisture content equal to the capillary moisture content. Note that the moisture transfer is modeled as a single phase flow, which means that the increase of the moisture content caused by dissolution of entrapped air in water is not incorporated.

Assuming a perfect hydraulic contact, as done in most modeling approaches of capillary transport between materials (see e.g. [20]), means that capillary pressure and liquid water flow rate are continuous across the interface [1]. For imperfect contact conditions at the interface, a resistance $R_{I F}$ is introduced. The interface has a zero thickness with no capacity, and the water flow across the interface is described by:

$$
g_{I F}=\frac{1}{R_{I F}} \cdot \Delta p_{c}
$$

with $\Delta p_{c}$ a jump in capillary pressure. In a first approach a constant interface resistance is assumed. The equations are solved using finite elements [8].

\subsection{Moisture transport properties}

To solve the governing equations, the knowledge of the bulk density, porosity, the capillary pressure curve and unsaturated permeability of the brick and the three types of mortars is needed. Material samples are prepared in the same way as described in section 2.1. Samples of the mortar are obtained by sawing the brick part carefully away from the masonry samples.

To determine the bulk density $\rho$ and open porosity $\phi_{0}$, samples are dried at $50^{\circ} \mathrm{C}$ and then vacuum saturated with distilled water according to the Belgian standard NBN-76. Table 1 gives the measurement results. A higher open porosity for the mould mortar (19\%) is measured, while the porosities of the wet cured mortar (16\%) and dry cured mortar (14\%) are lower.

It is interesting to compare the total porosity with the effective porosity $\phi_{\text {eff, }}$ which is defined as that part of the open porosity wetted during capillary uptake, or $\phi_{\text {eff }}=w_{c a p} / \rho_{l}$ with $\rho_{l}$ the density of liquid water. We observe that the effective porosities of mould mortar (13\%) and wet cured mortar (12\%) are quite similar, while the dry cured mortar shows a somewhat lower effective porosity (10\%).

The moisture capacity $C\left(p_{c}\right)$ is determined from the wetting capillary pressure curve $w\left(p_{c}\right)$. This curve is based on a combination of the sorption isotherm and mercury intrusion data. Adsorption isotherms are determined by placing dry samples in desiccators, in which a saturated salt solution provides a constant relative humidity. A mercury intrusion experiment consists of applying a set of increasing mercury pressures to a dry sample and measuring the corresponding mercury intrusion volume. Using the Young-Laplace equation and assuming cylindrical pores, the data can be recalculated into a drying capillary pressure curve. By combining the sorption and mercury intrusion data, the drying capillary pressure curve from vacuum saturation is obtained. Figure 7a shows the measurement data for the mould mortar. The wetting curve, which describes the equilibrium moisture content curve of an initially dry material during capillary uptake, is obtained from the drying curve lowering the maximum value to the capillary moisture content $w_{\text {cap }}$. It is noted that in this approach hysteresis is not considered. The wetting capillary pressure curve is described by a bimodal function $(k=2)$ of the van Genuchten type [6]: 
Postprint: Derluyn H, Janssen H, Carmeliet J, 2011. Influence of the nature of interfaces on the capillary transport in layered materials, Construction and Building Materials, 25: 3685-3693.

doi:10.1016/j.conbuildmat.2011.03.063

$w=w_{\text {cap }} \sum_{i=1}^{k} \frac{l_{i}}{\left(1+\left(a_{i} p_{c}\right)^{n_{i}}\right)^{m_{i}}}$ with $m_{i}=1-1 / n_{i}$

with $a$ and $n$ shape parameters, $l$ a weight parameter. Figure 7b compares the wetting curves for the different mortars and brick. The parameters are given in Table 2. The corresponding pore volume distributions of the mortars are given in Figure 7c. The pore volume distributions for the different mortars are similar consisting of a fine and coarse pore system. It is important to note that especially the dry cured mortar (and to a less extent the wet cured mortar) shows a lower volume of coarse pores. Coarse pores are known to contribute more importantly to moisture uptake resulting in higher capillary absorption coefficients. Therefore, the capillary absorption coefficient of the dry cured mortar is expected to be lower.

The capillary absorption coefficients $A_{\text {cap }}$ of the mortars are determined in a free water uptake experiment on dry samples. Table 1 gives the measured values. Mould mortar shows the highest value and the dry cured mortar the lowest capillary absorption coefficient. This is consistent with the observation that for the mould mortar a higher volume of coarse pores is active during capillary uptake compared to the dry cured mortar.

The unsaturated permeability of the brick and mortar is determined from the moisture diffusivity following the method proposed by Carmeliet et al. [4]. The moisture diffusivity is determined by a combination of a liquid diffusivity obtained from X-ray moisture content profile measurements [3] and a vapor diffusivity determined from vapor permeability measurements (Figure 8). The vapor permeability is measured using dry and wet cup tests (EN ISO 125722001 [21]) at three different relative humidities (33\%, 70\% and 92\% RH). Table 1 indicates that the vapor permeability is higher for the mould mortar and lower for wet and dry cured mortar. This indicates that wet and dry cured mortar probably have a more tortuous pore structure.

The moisture diffusivity is then recalculated into a moisture permeability using the capillary pressure curve, or $K\left(p_{c}\right)=D(w) . C\left(p_{c}\right)$. Figure 9a shows the moisture permeability curve for brick including measurement data, together with the permeability for the mould mortar. At low moisture content (high capillary pressure), the permeability curve describes the vapor flow, while at high moisture content (low capillary pressure) the permeability curve represents the dominant liquid water transport. The mortar shows a much lower liquid permeability compared to the brick and is also more vapor tight at low moisture contents (high capillary pressure range). Only in the intermediate capillary pressure range, where capillary condensation occurs in the important volume of hygroscopic pores, the mortar shows a higher permeability than brick. This is typical for materials showing both capillary and hygroscopic pores.

Figure $9 \mathrm{~b}$ gives the moisture permeability for the different mortars. The liquid water permeability is quite similar for the three mortars. This means that the main difference between the mortars is related to the pore volume wetted during capillary uptake (and thus the capillary moisture content $w_{\text {cap }}$ ) and not so much to the permeability. We remark that this is not in contradiction with the observed differences in capillary absorption coefficients between the mortars, since $A_{\text {cap }}$ represents an integrated moisture transport property combining both moisture capacity and permeability.

\subsection{Simulation results}

Figures 10a-c compare the measurement results and simulations of the cumulative inflow. The moisture transport properties as determined in section 3.2 are used. The inflow for the wet and dry cured mortar is too high when a perfect contact is assumed. This indicates that an interface resistance is present. A constant interface resistance is assumed and determined by 
Postprint: Derluyn H, Janssen H, Carmeliet J, 2011. Influence of the nature of interfaces on the capillary transport in layered materials, Construction and Building Materials, 25: 3685-3693.

doi:10.1016/j.conbuildmat.2011.03.063

inverse identification. For wet cured mortar, a resistance of $1.2510^{10} \mathrm{~m} / \mathrm{s}$ is obtained. For dry cured mortar a higher resistance of $2.510^{10} \mathrm{~m} / \mathrm{s}$ is found. The calculated flow rate across the interface is compared with the measurements in Figures 11a-c. Finally the moisture content profiles as obtained in the X-ray measurements are compared with simulations in Figure 12 for wet and dry cured mortar. A good agreement is obtained between measurement and simulations, which proves the existence of an interface resistance in the case of wet and dry cured mortar.

\section{Discussion}

It is interesting to examine the change of moisture transport in the mortar and the existence of an interface resistance due to the curing process in more detail. Simulations indicate respectively a lower and higher resistance for wet and dry cured mortar. Also the total open porosity and the effective porosity are depending on the curing process. The dry cured mortar shows a lower effective porosity, especially due to a reduction of the coarse pores, resulting in a lower capillary absorption coefficient. For the wet cured mortar the decrease in effective porosity and reduction of the coarse pore system is more limited.

To explain these differences in pore structure due to the curing process, the water extraction from the mortar to the brick during curing is measured. Brick samples are dried at $50^{\circ} \mathrm{C}$ and $3 \% \mathrm{RH}$. The bricks are then placed in vapor tight cups and fresh mortar is applied on one brick surface. The cup is closed to prevent evaporation. The mortar is then removed from the bricks after respectively 2, 4, 8, 15, 30, 45, 60 and 90 minutes of contact time. The amount of water taken up by the brick is determined by weighing the brick before applying the mortar and after removal of the mortar. Figure 13 gives the amount of water extracted from the mortar as a function of time for the wet cured and dry cured mortar. The amount of water taken up by the brick is expressed relative to the initial amount of water in the mortar when mixed. The uptake of water amounts to $30 \%$ for dry cured mortars and only to $6 \%$ for wet cured mortars. The initial water-cement ratio of the mortar is 0.5 . Using the amounts of water extracted from the mortar, we find that the water-cement ratio of the mortar decreases from 0.5 to respectively 0.47 for wet cured mortar and 0.35 for dry cured mortar. As already indicated in the introduction, the reduction of the water-cement ratio may explain the reduction of the porosity and change in pore structure (see [15-16]). In these publications it is also pointed out that the permeability depends not only on the porosity, but also on the pore size distribution. This paper clearly shows that the reduction of the water-cement ratio due to curing results in a decrease of total porosity, the effective porosity and especially the amount of coarse pores.

To explain the existence of an interface resistance, the interface between mortar and brick is analyzed microscopically. Representative microscopic images of the interface for wet cured and dry cured specimens are given in Figures 14 . At the interface of the dry cured mortar, air voids, also called compaction pores, are clearly visible, whereas in the wet cured mortar only air inclusions are found. The water extraction and reduction of water-cement ratio result in a fast compaction of mortar and the appearance of pores at the interface. A similar observation is described in Brocken et al. [13]. They found that only $20-30 \%$ of the surface area of the cured mortar is in good contact with the brick. We conclude that a strong reduction in watercement ratio, due to a low moisture content in the brick, can explain the imperfect contact in dry cured mortar.

The existence of an interface resistance for joint mortars may be further explained by the fact that the water extraction from mortar to brick incorporates a transport of fine cement particles towards the bond plane, resulting in a blocking of the pores and leading to an interface resistance between brick and mortar. Also the mismatch between the different pore systems of 
Postprint: Derluyn H, Janssen H, Carmeliet J, 2011. Influence of the nature of interfaces on the capillary transport in layered materials, Construction and Building Materials, 25: 3685-3693.

doi:10.1016/j.conbuildmat.2011.03.063

brick and mortar layer contribute to an interface resistance: the equivalent pore radius of the brick is a factor 100 larger than the equivalent pore radius of mortar. We also note that microcracks between mortar and brick due to drying shrinkage of the mortar may lead to an additional resistance. Further experimental analysis would be needed to study these phenomena.

\section{Conclusions}

Free water uptake experiments on brick-mortar samples perpendicular to the mortar joint were performed to study the capillary transport across the brick-mortar interface. Masonry samples with differently cured mortar joints were investigated: fresh mortar cured between capillary wet bricks and fresh mortar cured between oven dry bricks, respectively referred to as wet and dry cured mortar. As reference for a perfect hydraulic contact, a mortar cured in mould was placed in contact with the bricks with kaolin.

The measurements showed an important decrease of the cumulative inflow rate for dry cured mortar and to a less extent for wet cured mortar compared to the reference sample. Also the capillary moisture content attained in the mortar during water uptake was found to be lower for the dry cured mortar compared to the wet cured and reference mortar. Simulations showed the hydraulic contact to be imperfect for the wet and dry cured mortar, which means that an additional hydraulic resistance is present at the brick-mortar interface.

The water extraction from the fresh mortar during the first hour to the dry brick may explain these findings. This process results in a lower water cement factor and lower effective porosity, which reflects the pore volume wetted during capillary uptake. The lower effective porosity explains the lower capillary moisture content observed in the experiments. Pore volume distribution analysis showed also a lower amount of coarse pores for the dry cured mortar, resulting in a lower diffusivity and capillary absorption coefficient. The lower water cement factor may also result in the appearance of compaction pores, which explains the existence of an interface resistance. For the wet cured mortar, water extraction was found to be less important, resulting in a smaller change of the moisture transport properties of the mortar and in a lower interface resistance.

This investigation has clearly established the influences of the curing conditions on the hygric properties of mortar joints, by modification of transfer properties and introduction of interface resistances. The curing conditions are hence to be accounted for in hygrothermal evaluations of masonry constructions. The curing conditions moreover affect the porosity of the mortars, which in turn may influence their mechanical properties. The curing conditions equally affect the brick-mortar bond. Mechanical testing of mortars and masonry should therefore likewise consider the curing conditions of the mortar. Whereas this investigation targeted the capillary transport in layered materials, its implications reach out to other performance characteristics as well.

We finally remark that we considered in this analysis only water uptake normal to the brickmortar interface. Transport along the interface may also play an important role in the water uptake in masonry.

\section{Acknowledgements}

The experimental work done by M.Sc. student Elke Deridder is highly appreciated. This research was sponsored by the Agency for Innovation by Science and Technology in Flanders (IWT), SBO project IWT03175 (Structural damage due to dynamic excitations: a multidisciplinary approach). 
Postprint: Derluyn H, Janssen H, Carmeliet J, 2011. Influence of the nature of interfaces on the capillary transport in layered materials, Construction and Building Materials, 25: 3685-3693.

doi:10.1016/j.conbuildmat.2011.03.063

\section{References}

[1] Bear J, Bachmat Y. Introduction to Modelling of Transport Phenomena in Porous Media. Dordrecht: Kluwer Academic Publishers; 1990.

[2] Carmeliet J, Descamps F, Houvenaghel G. Multiscale network model for simulating liquid water and water vapour transfer properties of porous materials. Transport Porous Med 1999; 35: 67-88.

[3] Carmeliet J, Hens H, Roels S, Adan O, Brocken H, Cerny R et al. Determination of the liquid water diffusivity from transient moisture transfer experiments. J Therm Envelope Build Sci 2004; 27: 277-305.

[4] Carmeliet J, Janssen H, Derluyn H. An improved moisture diffusivity model for porous building materials. In: Proceedings of the $12^{\text {th }}$ Symposium for Building Physics; 2007, p. 22835.

[5] Carmeliet J, Roels S. Determination of the Isothermal Moisture Transport Properties of Porous building Materials. J Therm Envelope Build Sci 2001; 24: 183-210.

[6] Carmeliet J, Roels S. Determination of the moisture capacity of porous building materials. J Therm Envelope Build Sci 2002; 25: 209-37.

[7] Hagentoft C.E, Kalagasidis AS, Adl-Zarrabi B, Roels S, Carmeliet J, Hens H et al. Assessment Method for Numerical Prediction Models for Combined Heat, Air and Moisture Transfer in Building Components: Benchmarks for One-dimensional Cases. J Therm Envelope Build Sci 2004; 27: 327-52.

[8] Janssen H, Blocken B, Carmeliet J. Conservative modelling of the moisture and heat transfer in building components under atmospheric excitation. Int J Heat Mass Tran 2007; 50: 1128-40.

[9] de Freitas VP, Abrantes V, Crausse P. Moisture migration in building walls - Analysis of the interface phenomena. Build Environ 1996; 31: 99-108.

[10] Holm A, Krus M, Künzel HM. Feuchtetransport über Materialgrenzen im Mauerwerk. Int. Zeitschrift für Bauinstandsetzen 1996; 2: 375-96.

[11] Qui X, Haghighat F, Kumaran K. Moisture transport across interfaces between autoclaved aerated concrete and mortar. J Therm Envelope Build Sci 2003; 26: 213-236. [12] Brocken HJP. Moisture transfer in brick masonry: the grey area between bricks. The Netherlands, T.U. Eindhoven: PhD Thesis; 1998.

[13] Brocken HJP, Spiekman ME, Pel L, Kopinga K, Larbi JA. Water extraction out of mortar during brick laying: a NMR study. Mater Struct 1998; 31: 49-57.

[14] de Rooij MR, Groot CJWP. A closer look at salt loaded microstructures. Heron 2006, 51: 47-60.

[15] Nyame BK, Illston JM. Relationships between permeability and pore structure of hardened cement paste. Mag Concrete Res 1981; 33: 139-46.

[16] Goto S, Roy DM. The effect of W/C ratio and curing temperature on the permeability of hardened cement paste, Cement Concrete Res 1981; 11: 575-79.

[17] Sanjuán MA, Muñoz-Martialay R. Influence of the water/cement ratio on the air permeability of concrete, J Mater Sci 1996; 31: 2829-32.

[18] Roels S, Carmeliet J. Analysis of moisture flow in porous materials using microfocus Xray radiography. Int J Heat Mass Tran 2006; 49: 4762-72.

[19] Hall C, Hoff WD. Water transport in brick, stone and concrete. New York: Spon Press; 2002.

[20] Roels S, Carmeliet J, Hens H. Modelling unsaturated moisture transport in heterogeneous limestone. Part 2, Macroscopic simulations. Transport Porous Med 2003; 52: 351-69. [21] EN ISO 12572. Hygrothermal performance of building materials and products Determination of water vapor transmission properties. 2001. 
Postprint: Derluyn H, Janssen H, Carmeliet J, 2011. Influence of the nature of interfaces on the capillary transport in layered materials, Construction and Building Materials, 25: 3685-3693.

doi:10.1016/j.conbuildmat.2011.03.063

\section{Figure captions}

Figure 1: X-ray projection image of the capillary uptake experiment on masonry specimen with mould mortar. The water front in the mortar is clearly visible. The image shows the geometry and average dimensions of the masonry samples.

Figure 2: Moisture content profiles in masonry specimen with wet cured mortar obtained by $\mathrm{X}$-ray measurements.

Figure 3: Moisture content profiles in mortar joint obtained by X-ray measurements for masonry specimen with: (a) mortar cured in mould; (b) mortar cured between capillary saturated bricks; (c) mortar cured between dry bricks.

Figure 4: Cumulative moisture inflow for masonry specimens with differently cured mortar joints in function of square root of time.

Figure 5: Cumulative moisture inflow in mortar joint for masonry specimens with differently cured mortar joints in function of square root of time.

Figure 6: Moisture inflow rate into the mortar joint for masonry specimens with differently cured mortar joints in function of square root of time.

Figure 7: (a) Drying and wetting capillary pressure curve for mould mortar; (b) comparison of the wetting capillary pressure curve for brick and mould, wet and dry cured mortar; (c) pore size distribution of mortars wetted during capillary uptake.

Figure 8: Moisture diffusivity of mould mortar.

Figure 9: (a) Comparison of the permeability of brick with mould mortar; (b) comparison of the permeability curves of mould, wet and dry cured mortar.

Figure 10: Comparison of measured and simulated cumulative moisture inflow curve for perfect and imperfect hydraulic contact: (a) mould mortar; (b) wet cured mortar; (c) dry cured mortar.

Figure 11: Comparison of measured and simulated moisture inflow rate for perfect and imperfect hydraulic contact: (a) mould mortar; (b) wet cured mortar; (c) dry cured mortar.

Figure 12: Comparison of measured and simulated moisture content profiles for imperfect hydraulic contact: (a) wet cured mortar; (b) dry cured mortar (point line: measurement; full line: simulation).

Figure 13: Water extraction (with standard deviation) from fresh mortar to brick as a percentage of the total water initially present in the mortar.

Figure 14: (a) Microscopic image (magnification x 15) of interface between brick and wet cured mortar; (b) microscopic image (magnification x 15) of interface between brick and dry cured mortar. 
Postprint: Derluyn H, Janssen H, Carmeliet J, 2011. Influence of the nature of interfaces on the capillary transport in layered materials, Construction and Building Materials, 25: 3685-3693.

doi:10.1016/j.conbuildmat.2011.03.063

\section{Tables}

Table 1. Moisture transport properties.

\begin{tabular}{l|c|c|c|c}
\hline & brick & $\begin{array}{c}\text { mould } \\
\text { mortar }\end{array}$ & $\begin{array}{c}\text { wet cured } \\
\text { mortar }\end{array}$ & $\begin{array}{c}\text { dry cured } \\
\text { mortar }\end{array}$ \\
\hline open porosity $(-)$ & 0.209 & 0.19 & 0.16 & 0.14 \\
bulk density $\left(\mathrm{kg} / \mathrm{m}^{3}\right)$ & 2087 & 2092 & 2166 & 2232 \\
capillary moisture content $\left(\mathrm{kg} / \mathrm{m}^{3}\right)$ & 130 & 130 & 120 & 100 \\
capillary absorption coefficient $\left(\mathrm{kg} / \mathrm{m}^{2} \mathrm{~s}^{0.5}\right)$ & 0.116 & 0.019 & 0.015 & 0.010 \\
dry vapor permeability (s) & $6.09 \mathrm{E}-12$ & $1.46 \mathrm{E}-12$ & $0.54 \mathrm{E}-12$ & $0.43 \mathrm{E}-12$ \\
\hline
\end{tabular}

Table 2. Parameters of capillary pressure curve (equation 7).

\begin{tabular}{l|cc|cc|cc|cc}
\hline & \multicolumn{2}{|c|}{ brick } & \multicolumn{2}{c|}{ mould mortar } & \multicolumn{2}{c|}{ wet cured mortar } & \multicolumn{2}{c}{ dry cured mortar } \\
\hline $\mathrm{l}_{1}, \mathrm{l}_{2}$ & 0.846 & 0.154 & 0.426 & 0.574 & 0.512 & 0.488 & 0.657 & 0.343 \\
$\mathrm{a}_{1}, \mathrm{a}_{2}$ & $1.410^{-5}$ & $9.010^{-6}$ & $2.410^{-8}$ & $2.110^{-7}$ & $2.510^{-8}$ & $2.410^{-7}$ & $310^{-8}$ & $2.910^{-7}$ \\
$\mathrm{n}_{1}, \mathrm{n}_{2}$ & 4 & 1.69 & 2.34 & 2.68 & 2.31 & 2.33 & 2.14 & 3.24 \\
\hline
\end{tabular}


Postprint: Derluyn H, Janssen H, Carmeliet J, 2011. Influence of the nature of interfaces on the capillary transport in layered materials, Construction and Building Materials, 25: 3685-3693.

Figure 1

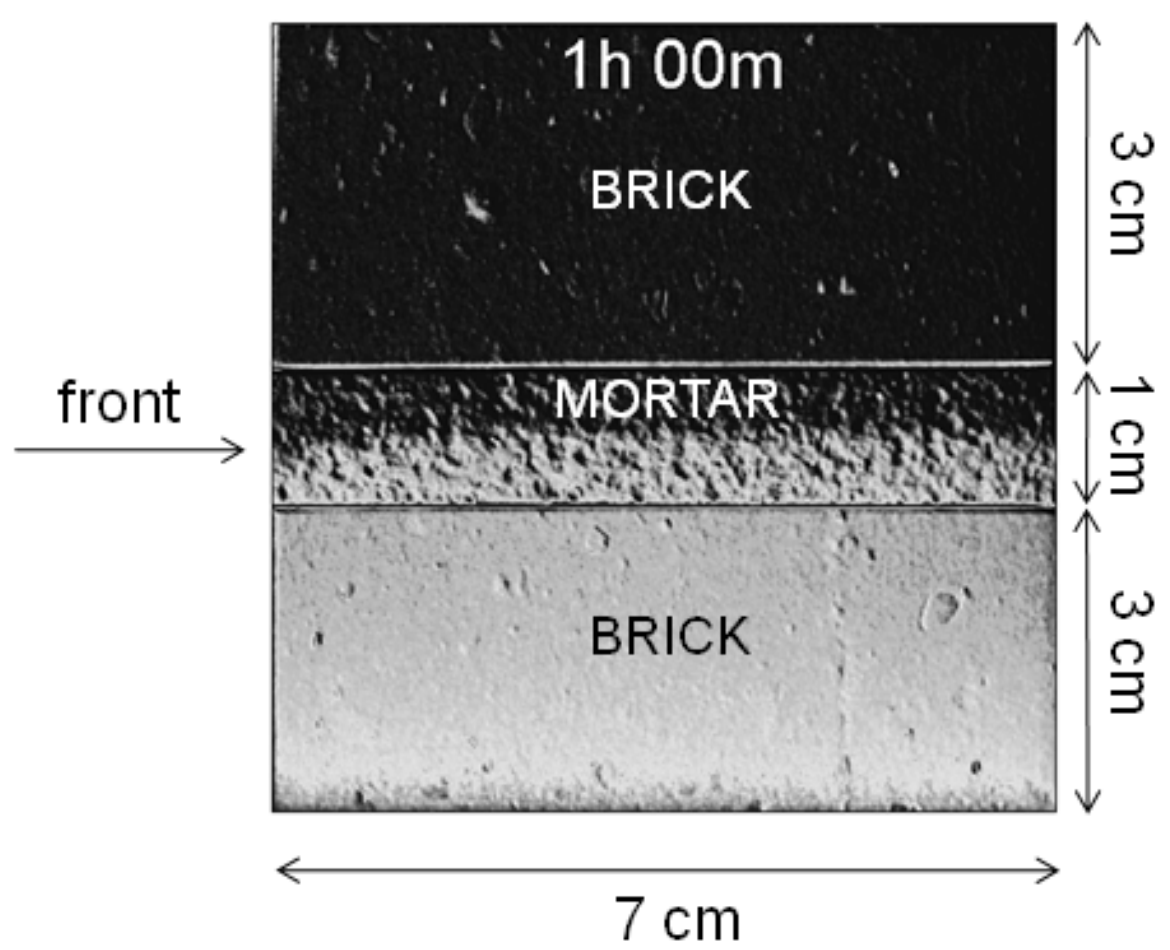

Figure 2

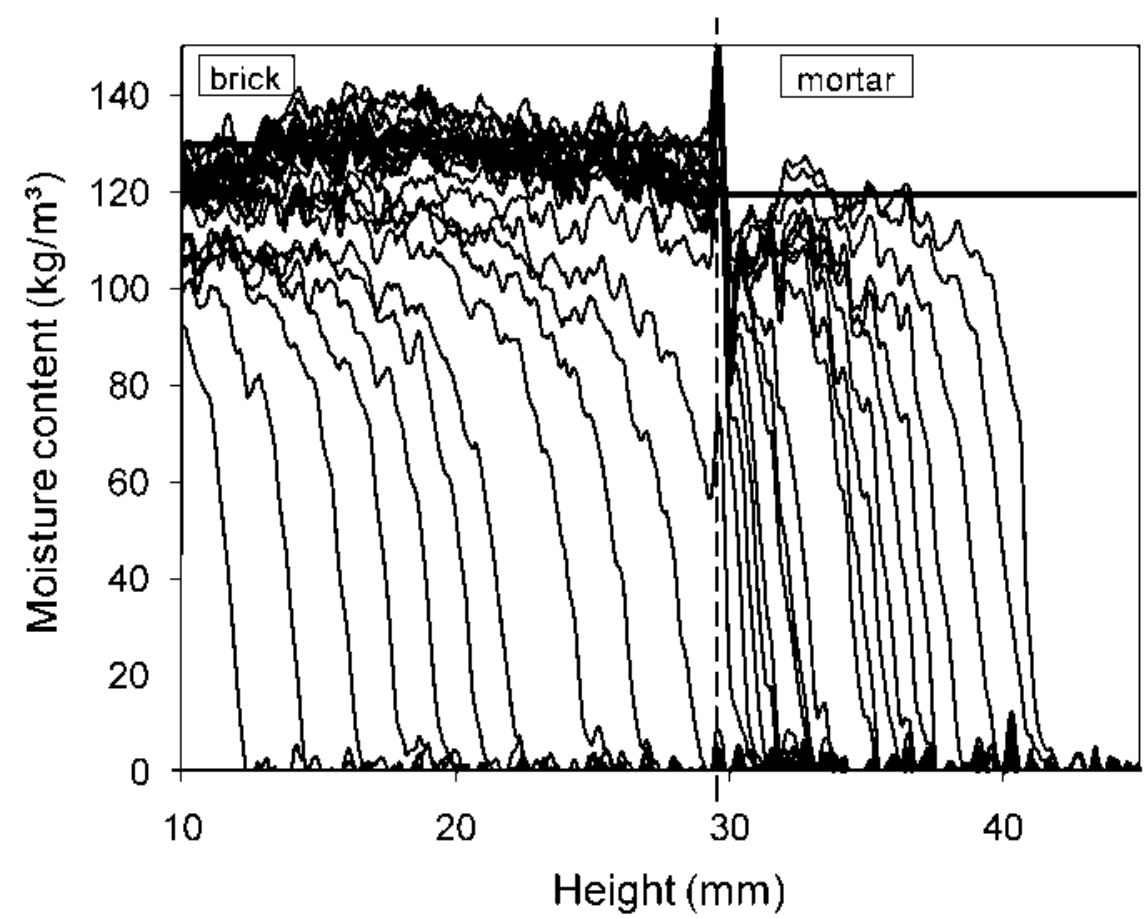


Postprint: Derluyn H, Janssen H, Carmeliet J, 2011. Influence of the nature of interfaces on the capillary transport in layered materials, Construction and Building Materials, 25: 3685-3693.

Figure 3

(a)

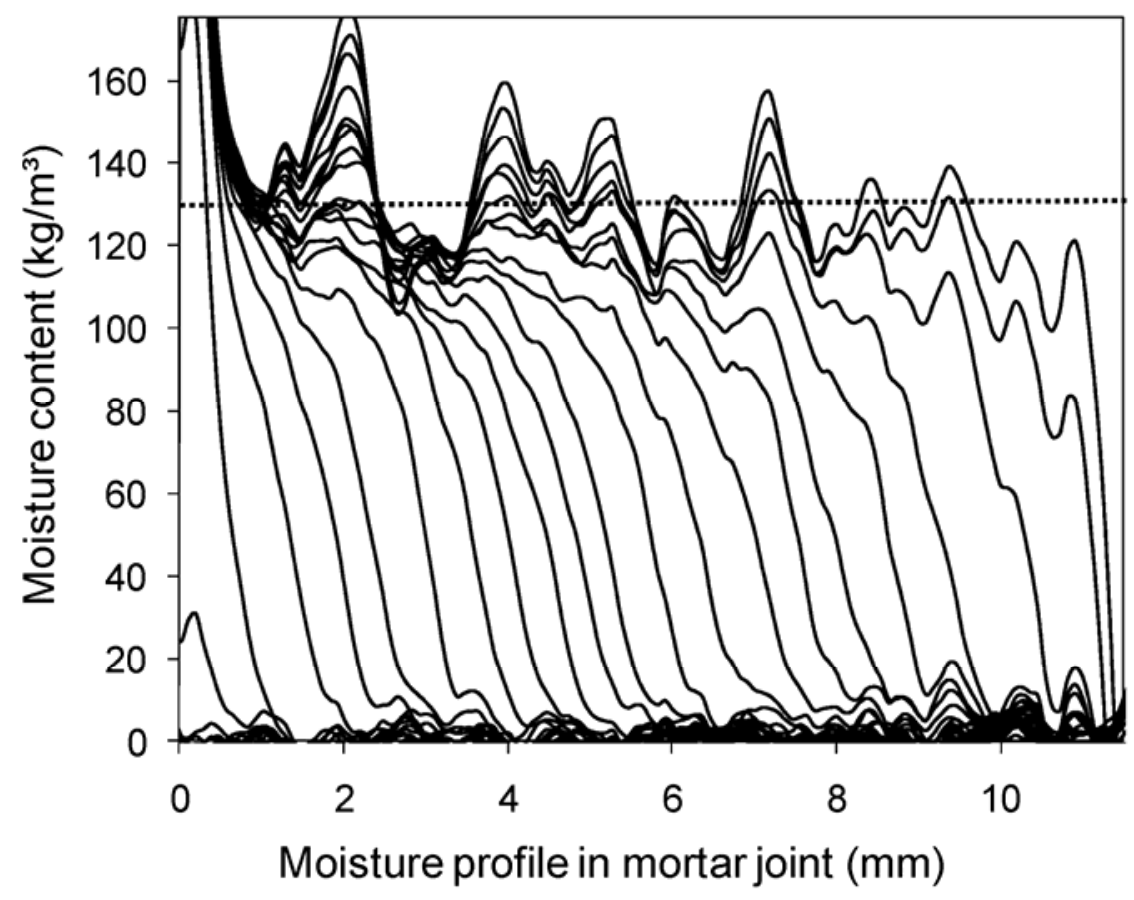

(b)

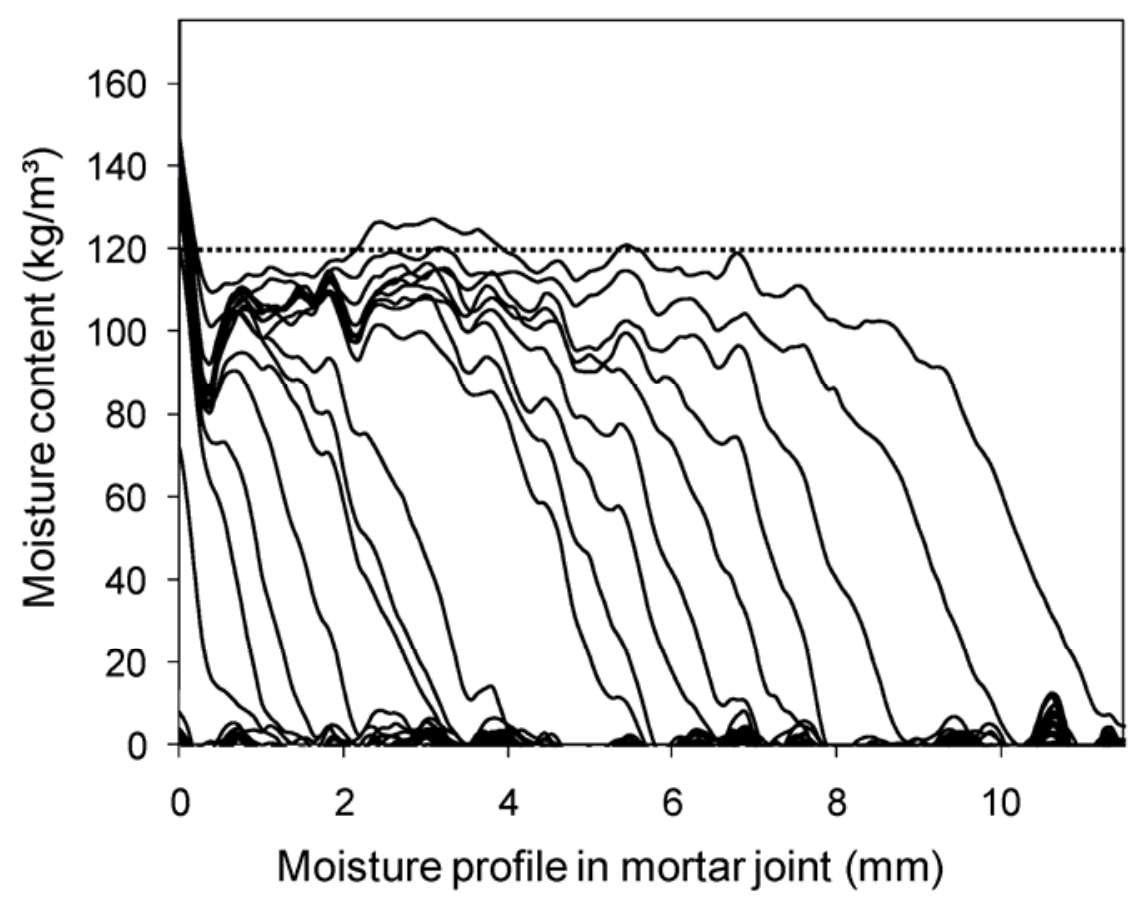


Postprint: Derluyn H, Janssen H, Carmeliet J, 2011. Influence of the nature of interfaces on the capillary transport in layered materials, Construction and Building Materials, 25: 3685-3693.

doi:10.1016/j.conbuildmat.2011.03.063

(c)

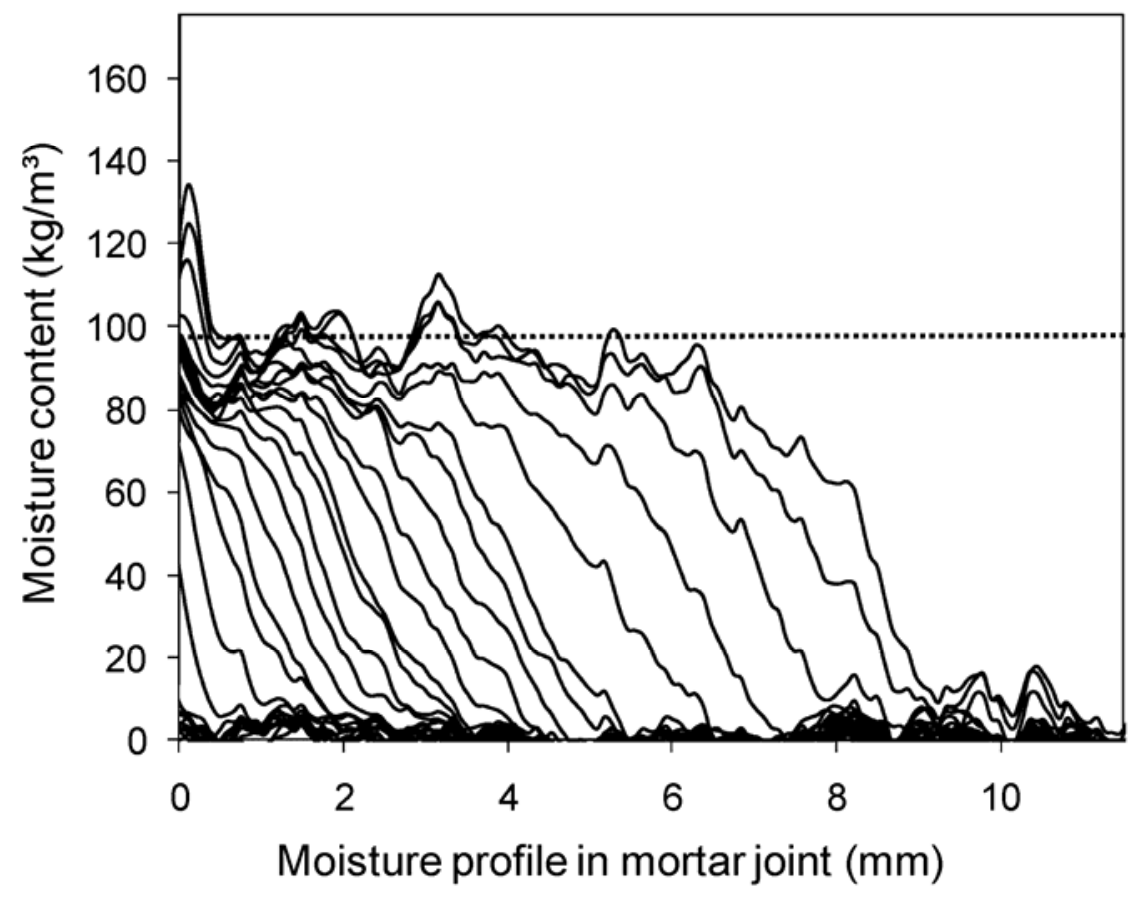

Figure 4

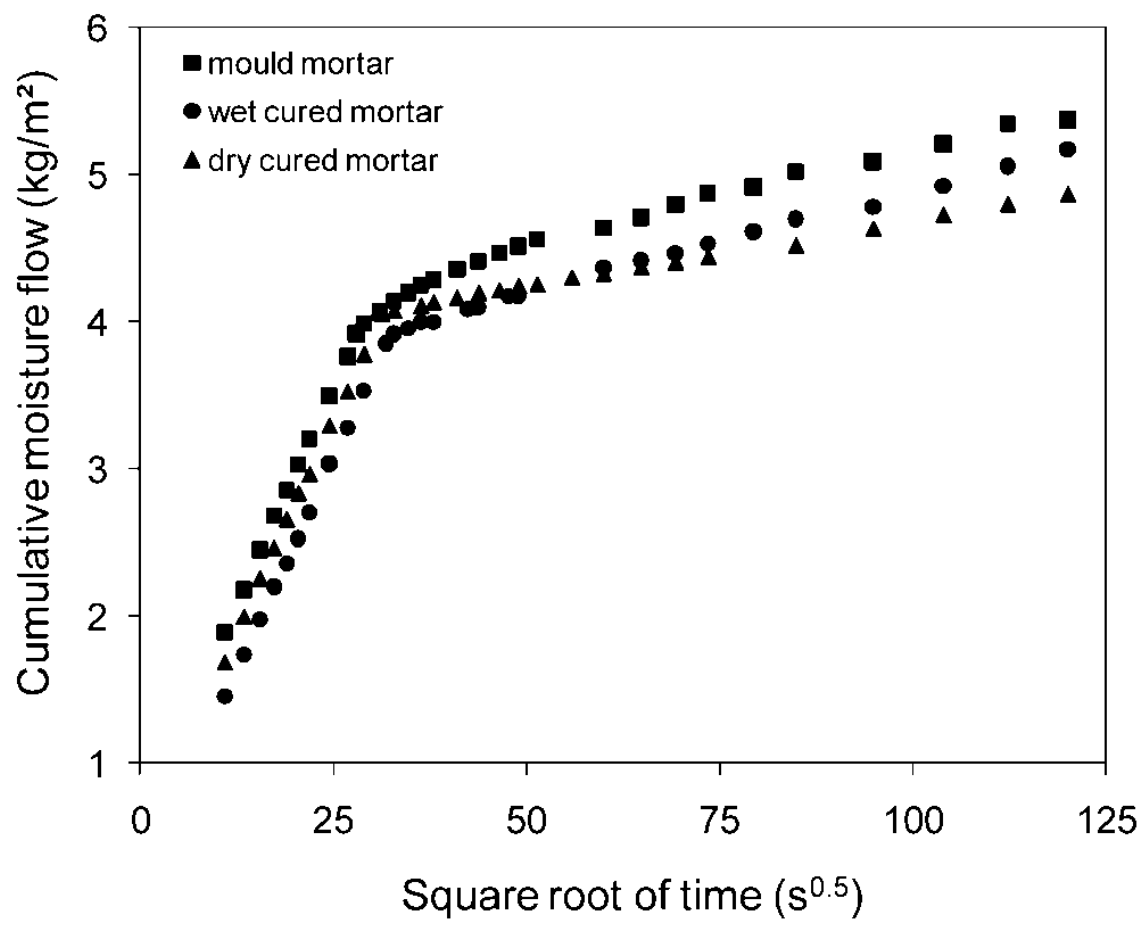


Postprint: Derluyn H, Janssen H, Carmeliet J, 2011. Influence of the nature of interfaces on the capillary transport in layered materials, Construction and Building Materials, 25: 3685-3693.

doi:10.1016/j.conbuildmat.2011.03.063

Figure 5

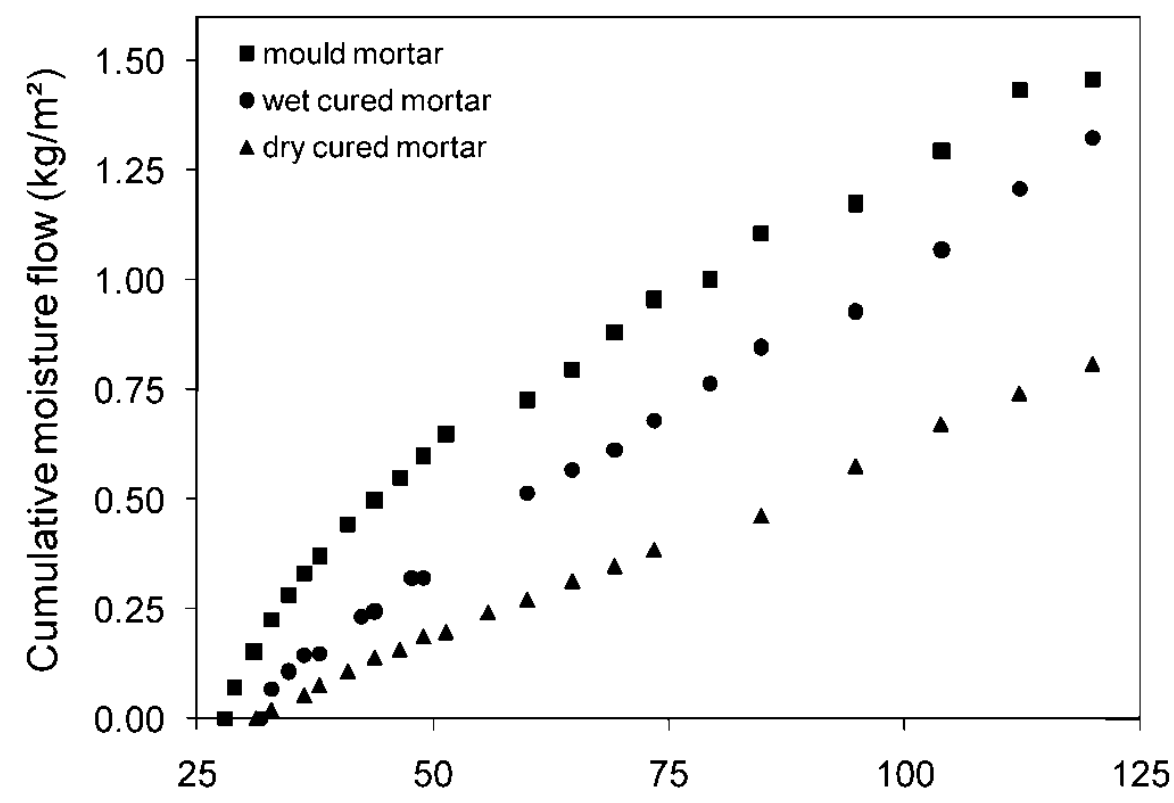

Square root of time $\left(s^{0.5}\right)$

Figure 6

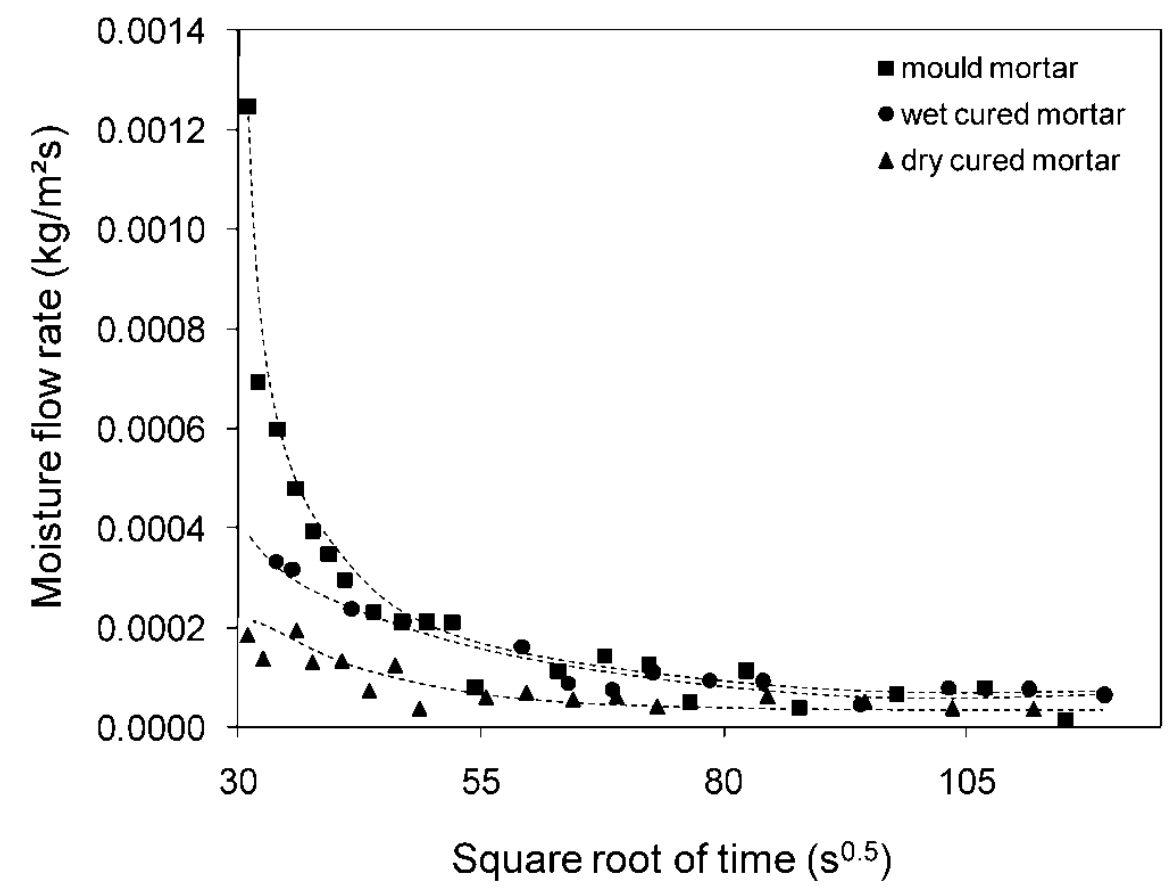


Postprint: Derluyn H, Janssen H, Carmeliet J, 2011. Influence of the nature of interfaces on the capillary transport in layered materials, Construction and Building Materials, 25: 3685-3693.

doi:10.1016/j.conbuildmat.2011.03.063

Figure 7

(a)

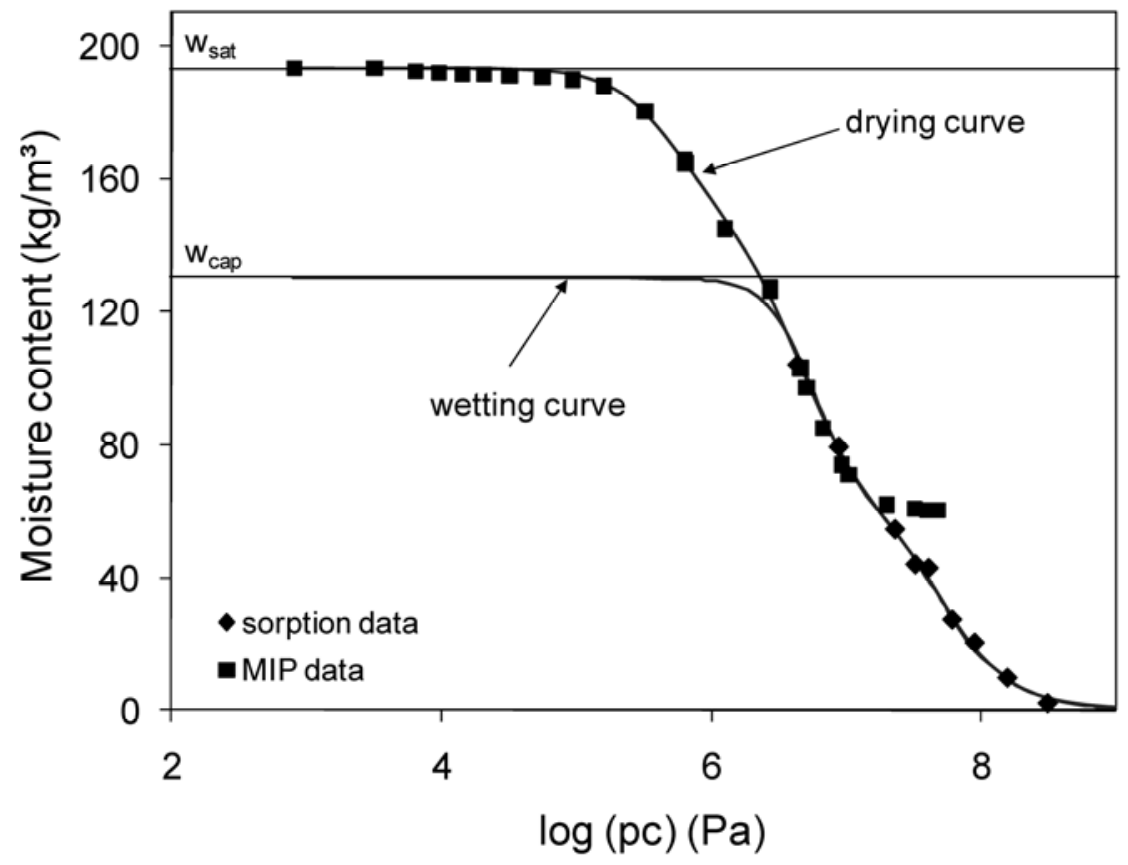

(b)

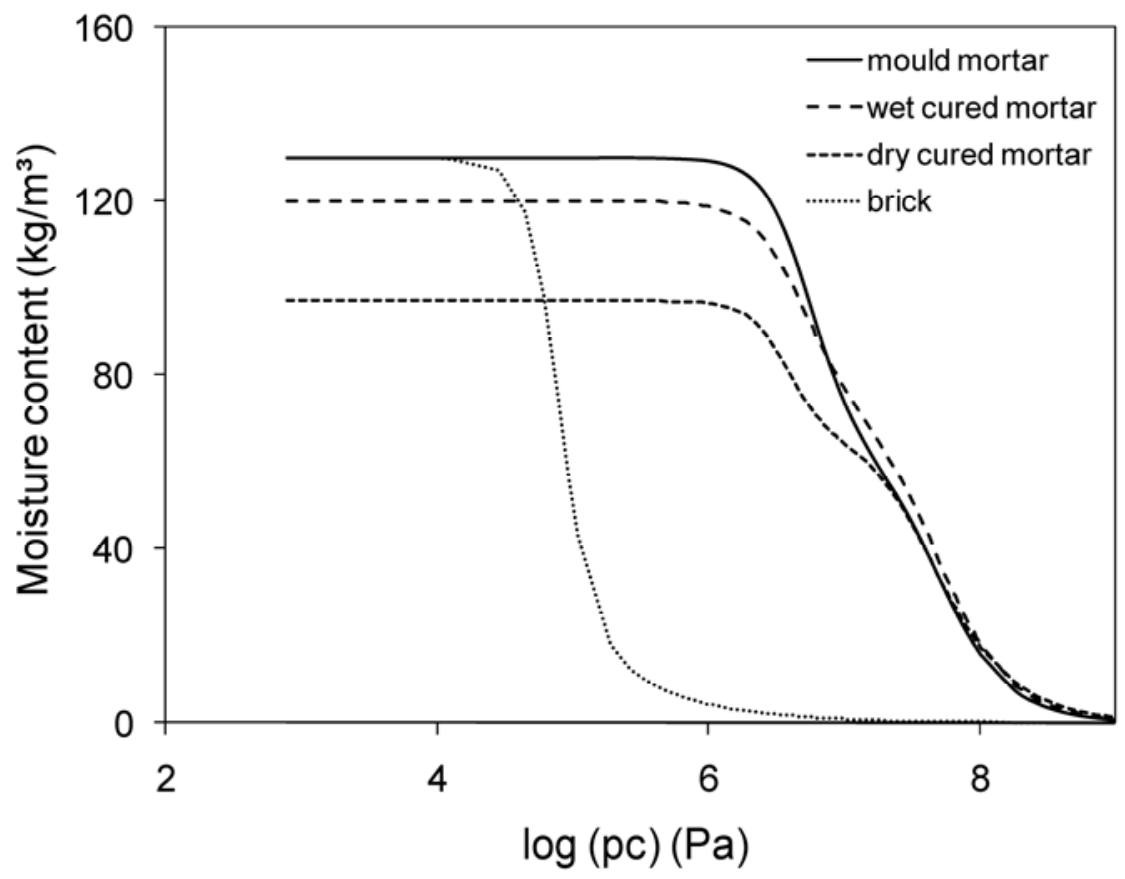


Postprint: Derluyn H, Janssen H, Carmeliet J, 2011. Influence of the nature of interfaces on the capillary transport in layered materials, Construction and Building Materials, 25: 3685-3693.

doi:10.1016/j.conbuildmat.2011.03.063

(c)

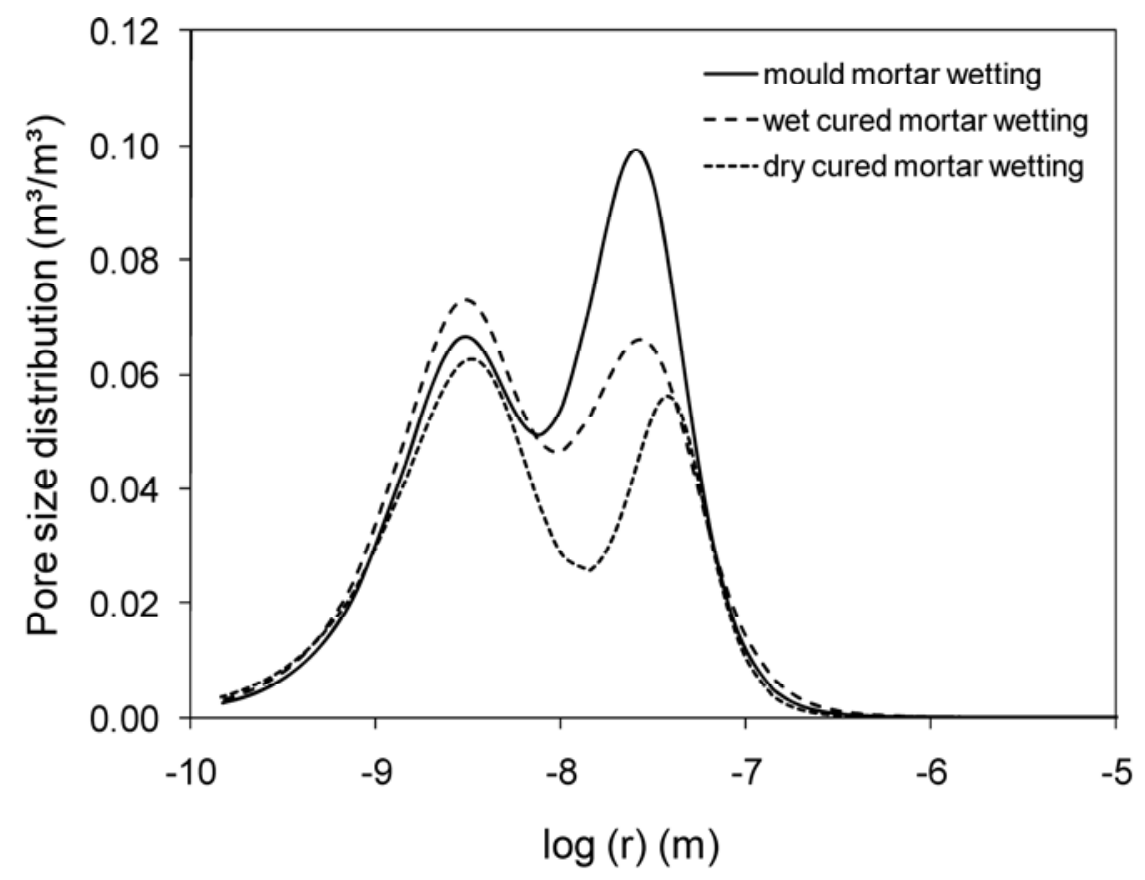

Figure 8

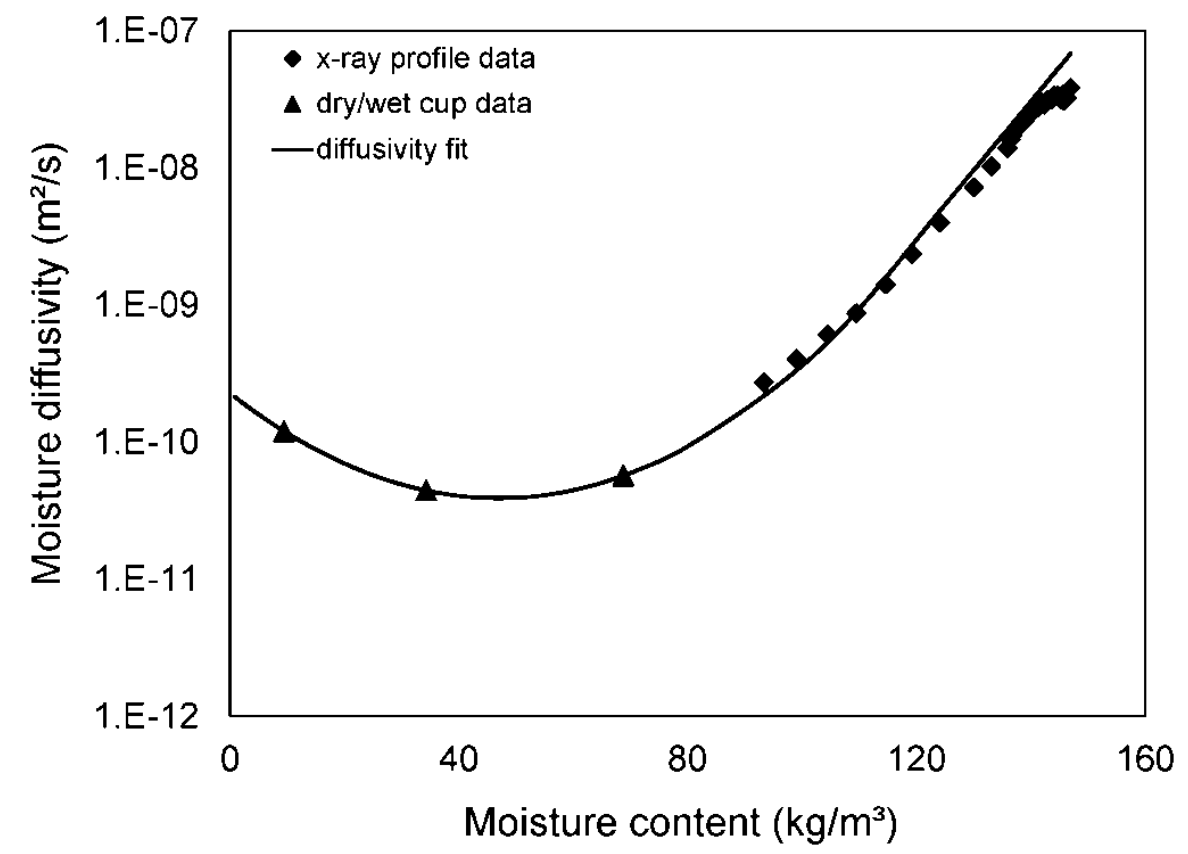


Postprint: Derluyn H, Janssen H, Carmeliet J, 2011. Influence of the nature of interfaces on the capillary transport in layered materials, Construction and Building Materials, 25: 3685-3693.

doi:10.1016/j.conbuildmat.2011.03.063

Figure 9

(a)

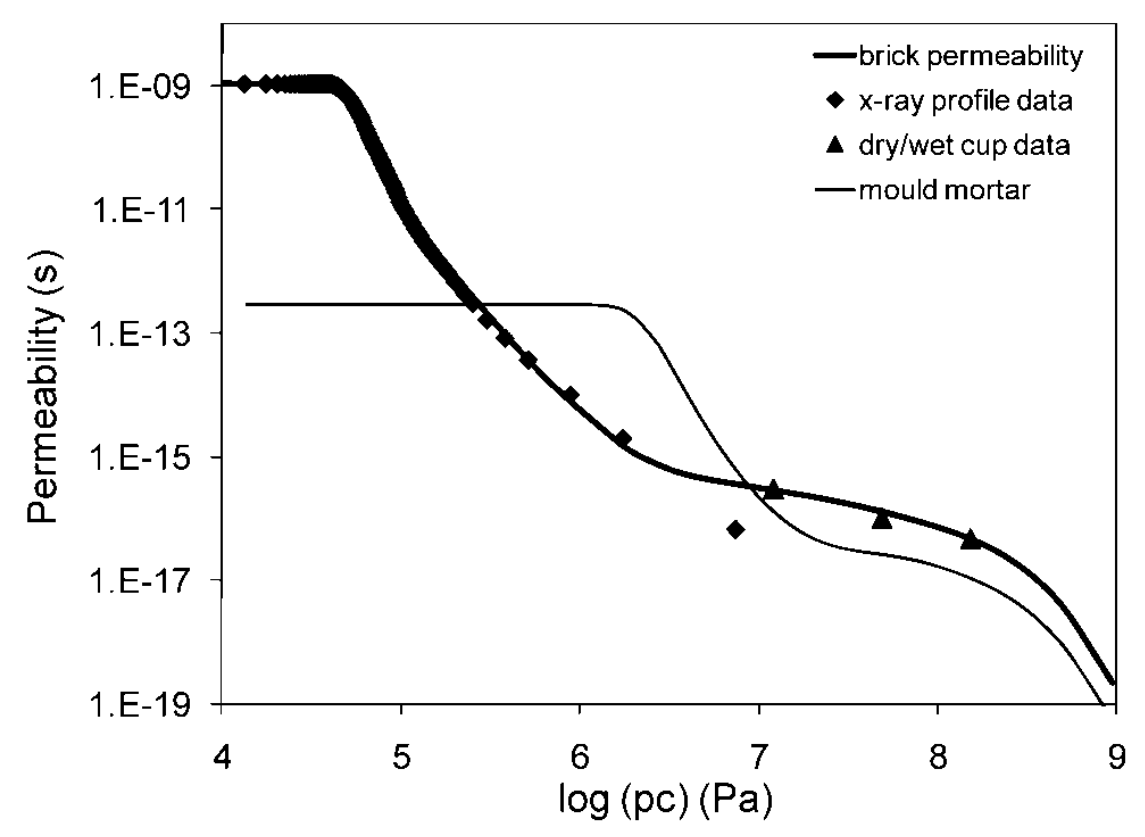

(b)

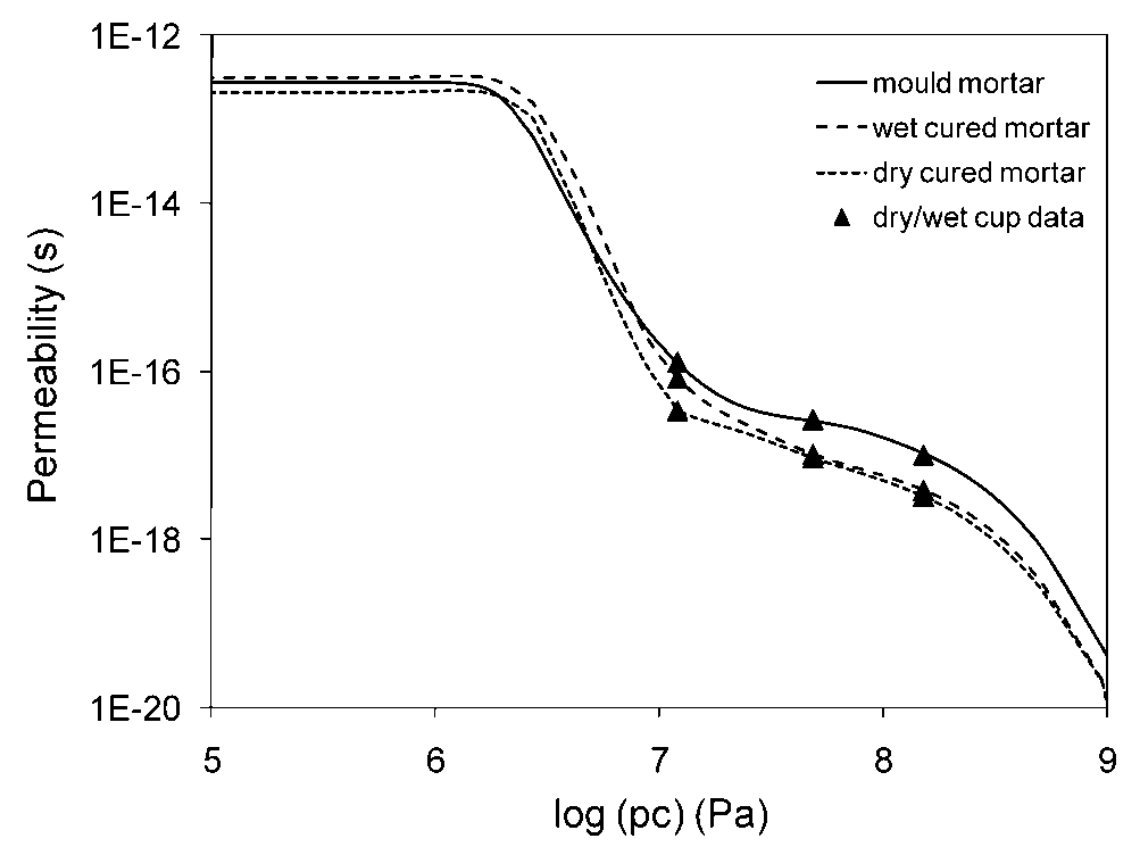


Postprint: Derluyn H, Janssen H, Carmeliet J, 2011. Influence of the nature of interfaces on the capillary transport in layered materials, Construction and Building Materials, 25: 3685-3693.

doi:10.1016/j.conbuildmat.2011.03.063

\section{Figure 10}

(a)

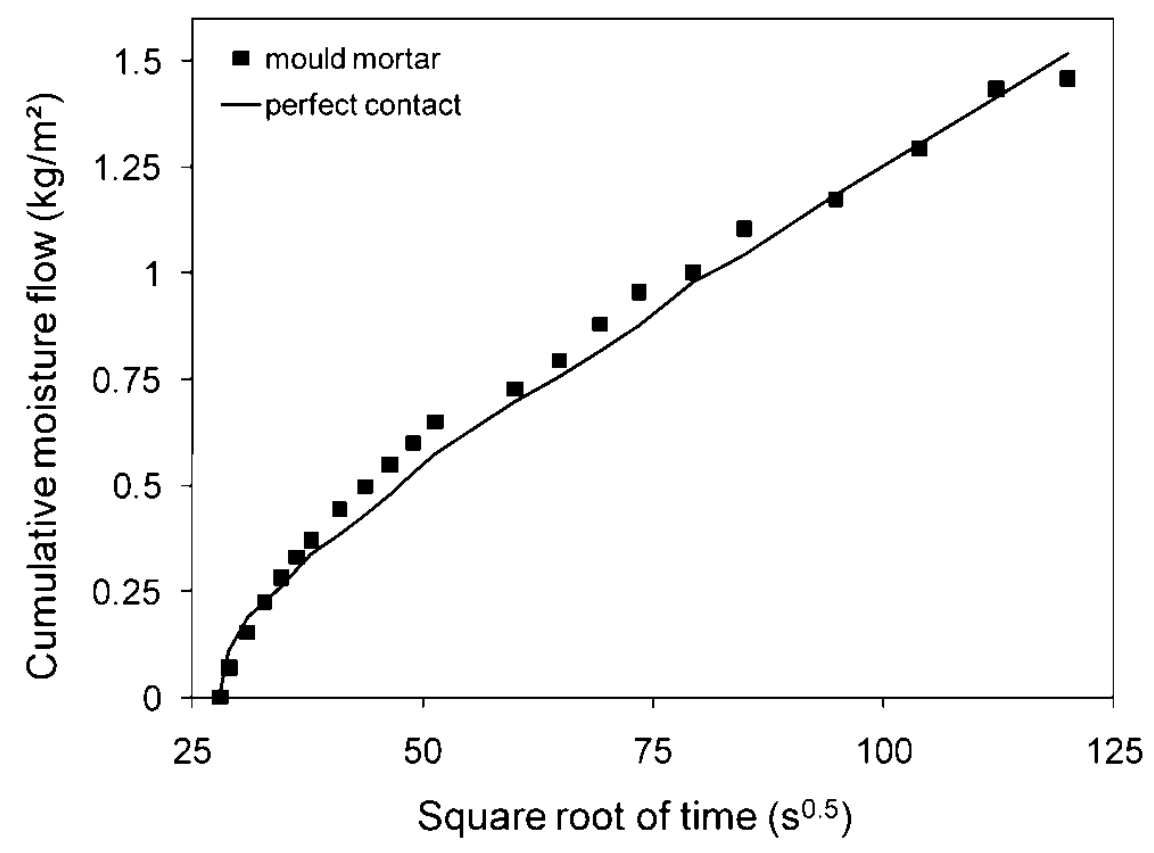

(b)

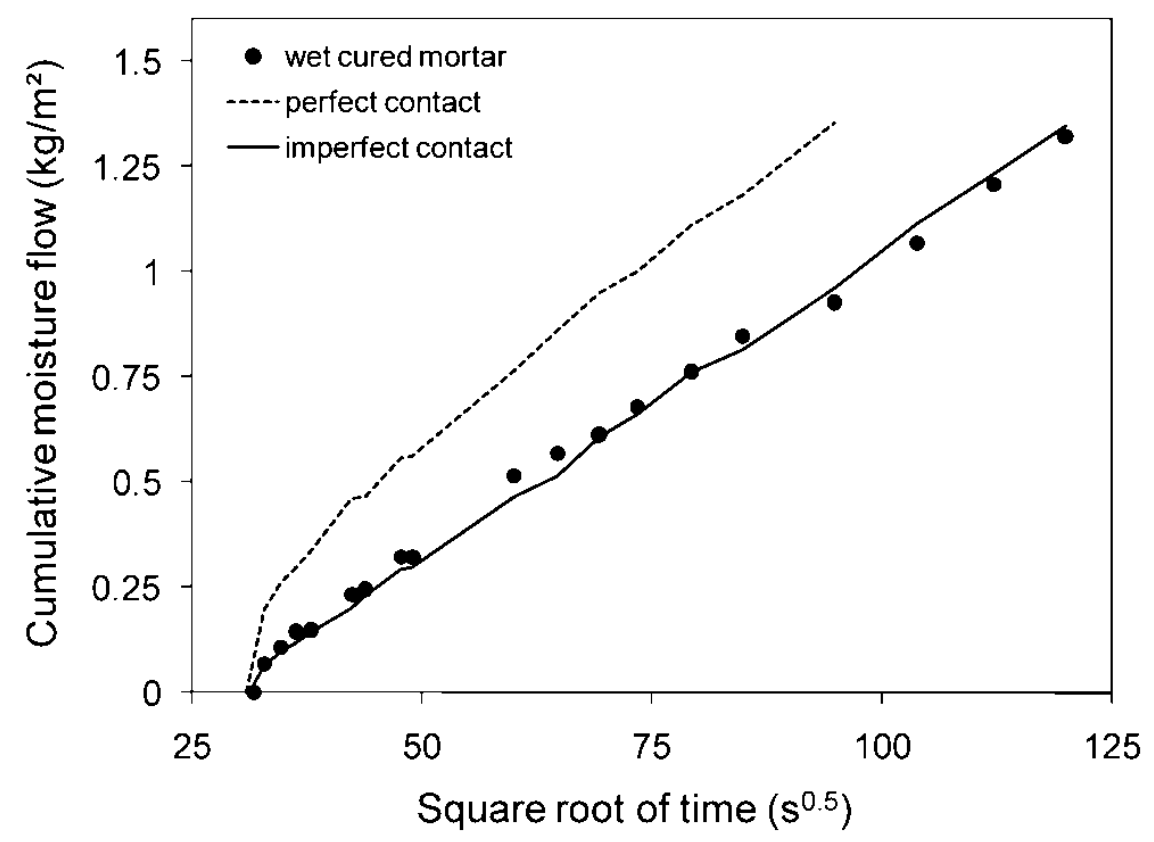


Postprint: Derluyn H, Janssen H, Carmeliet J, 2011. Influence of the nature of interfaces on the capillary transport in layered materials, Construction and Building Materials, 25: 3685-3693.

(c)

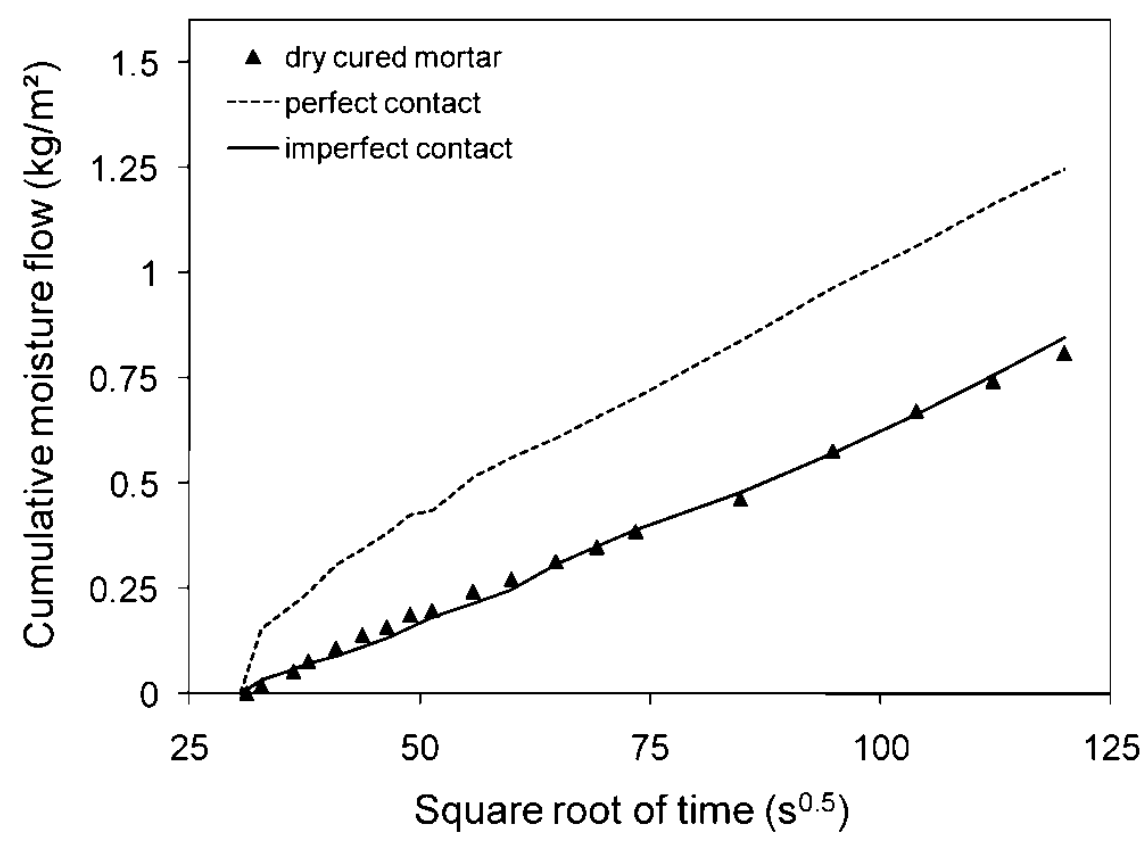

Figure 11

(a)

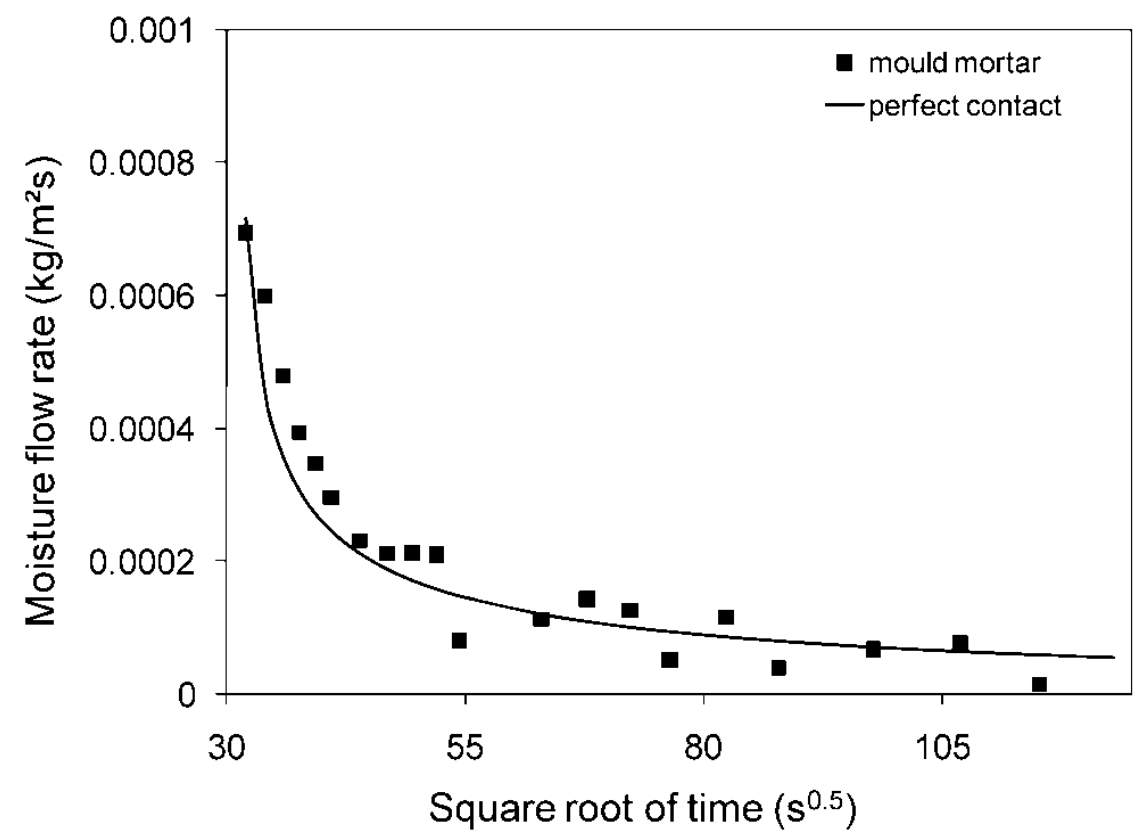


Postprint: Derluyn H, Janssen H, Carmeliet J, 2011. Influence of the nature of interfaces on the capillary transport in layered materials, Construction and Building Materials, 25: 3685-3693.

doi:10.1016/j.conbuildmat.2011.03.063

(b)

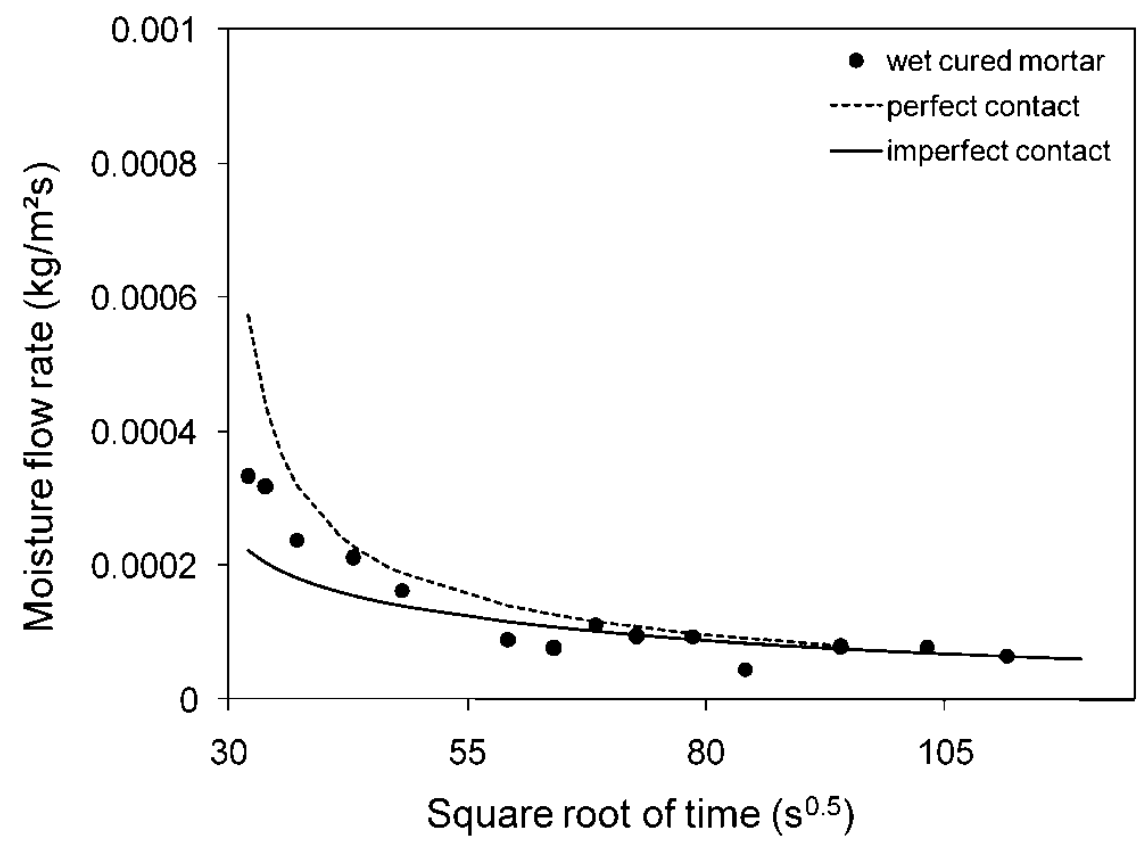

(c)

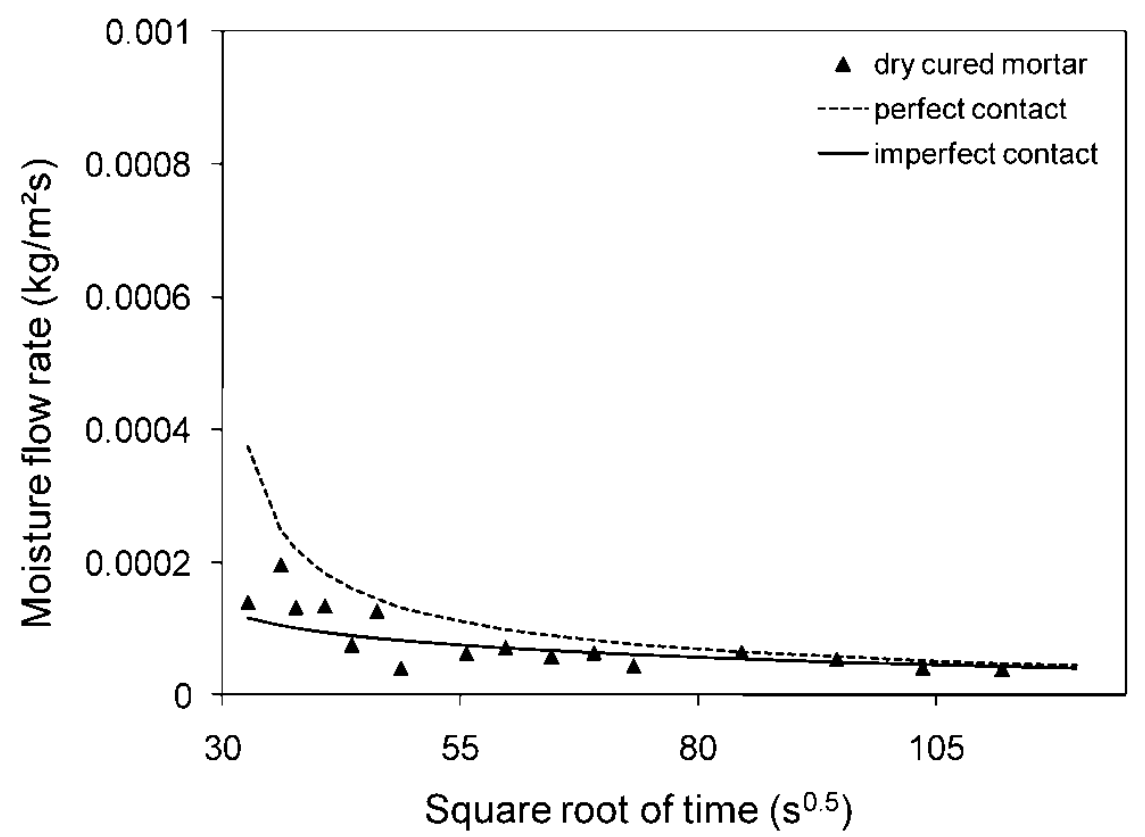


Postprint: Derluyn H, Janssen H, Carmeliet J, 2011. Influence of the nature of interfaces on the capillary transport in layered materials, Construction and Building Materials, 25: 3685-3693.

\section{Figure 12}

(a)

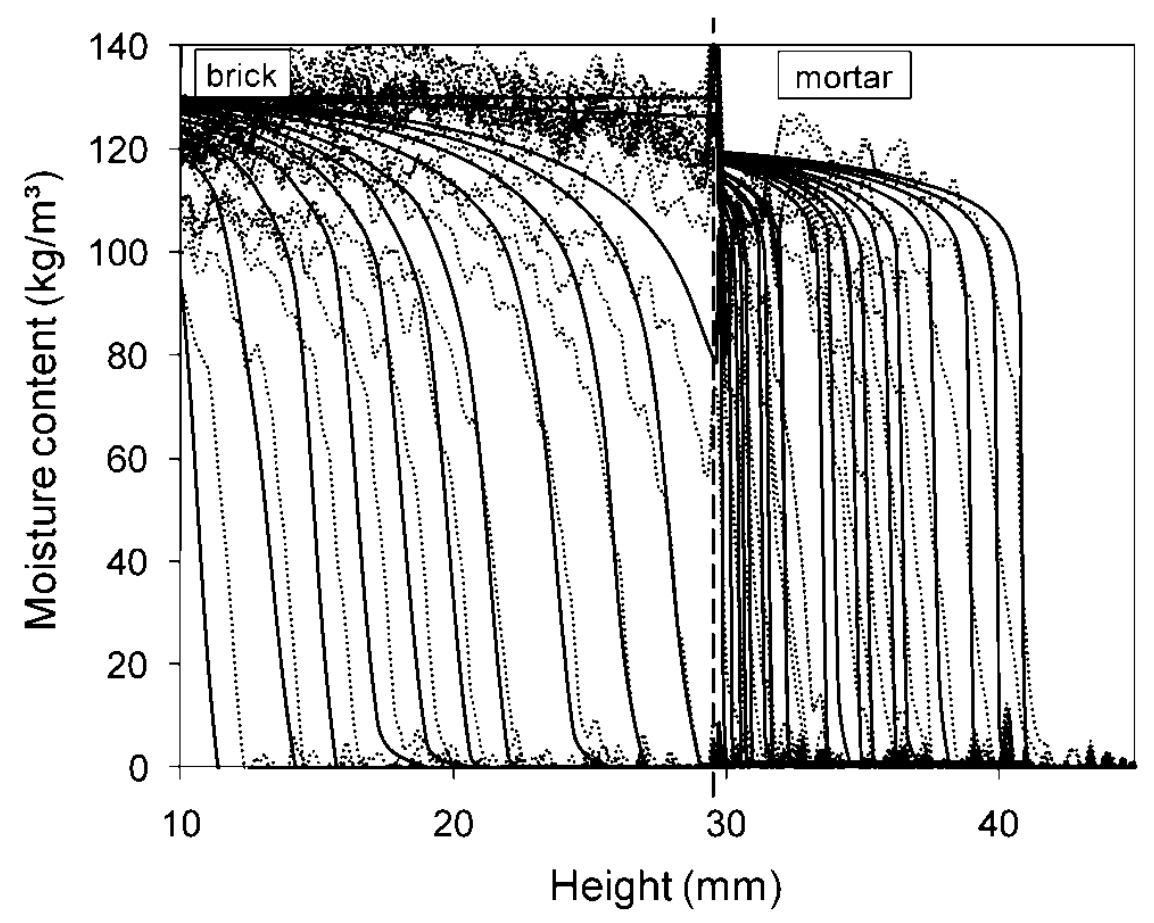

(b)

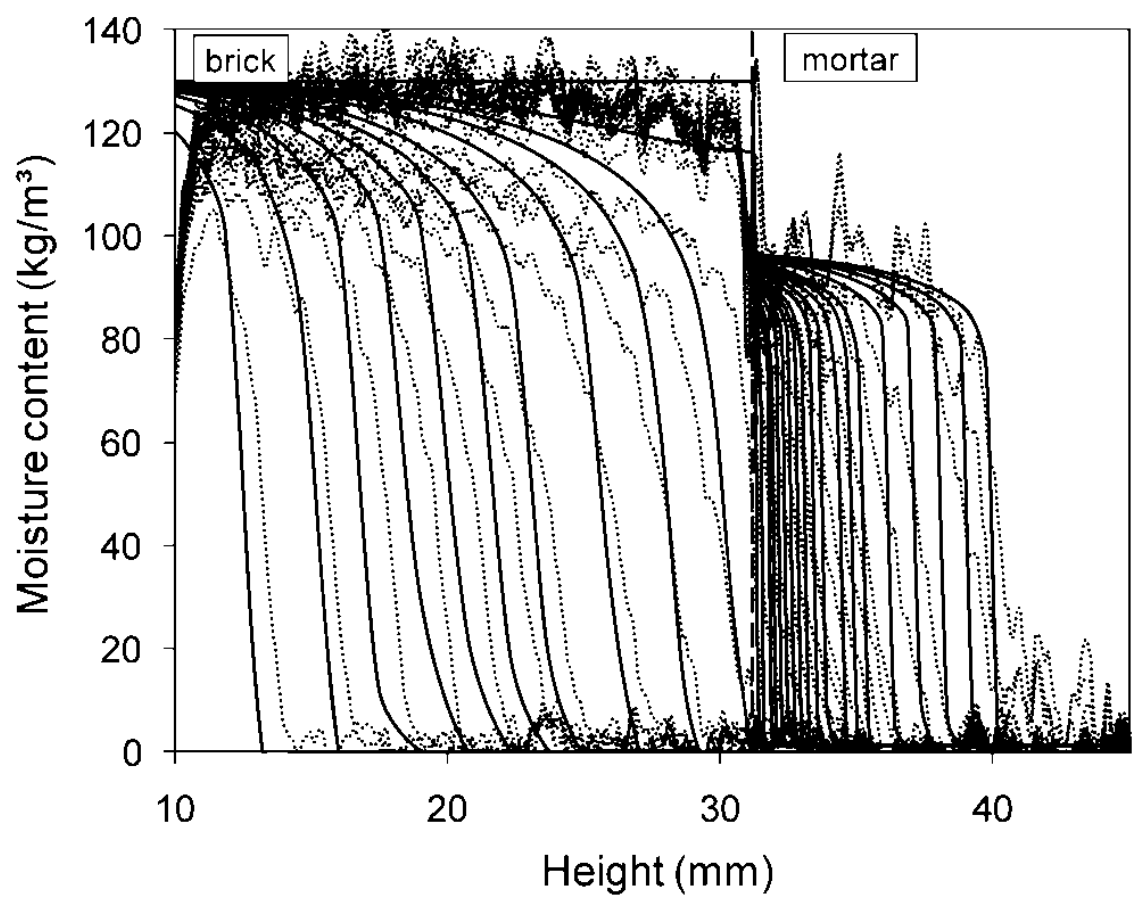


Postprint: Derluyn H, Janssen H, Carmeliet J, 2011. Influence of the nature of interfaces on the capillary transport in layered materials, Construction and Building Materials, 25: 3685-3693.

doi:10.1016/j.conbuildmat.2011.03.063

\section{Figure 13}

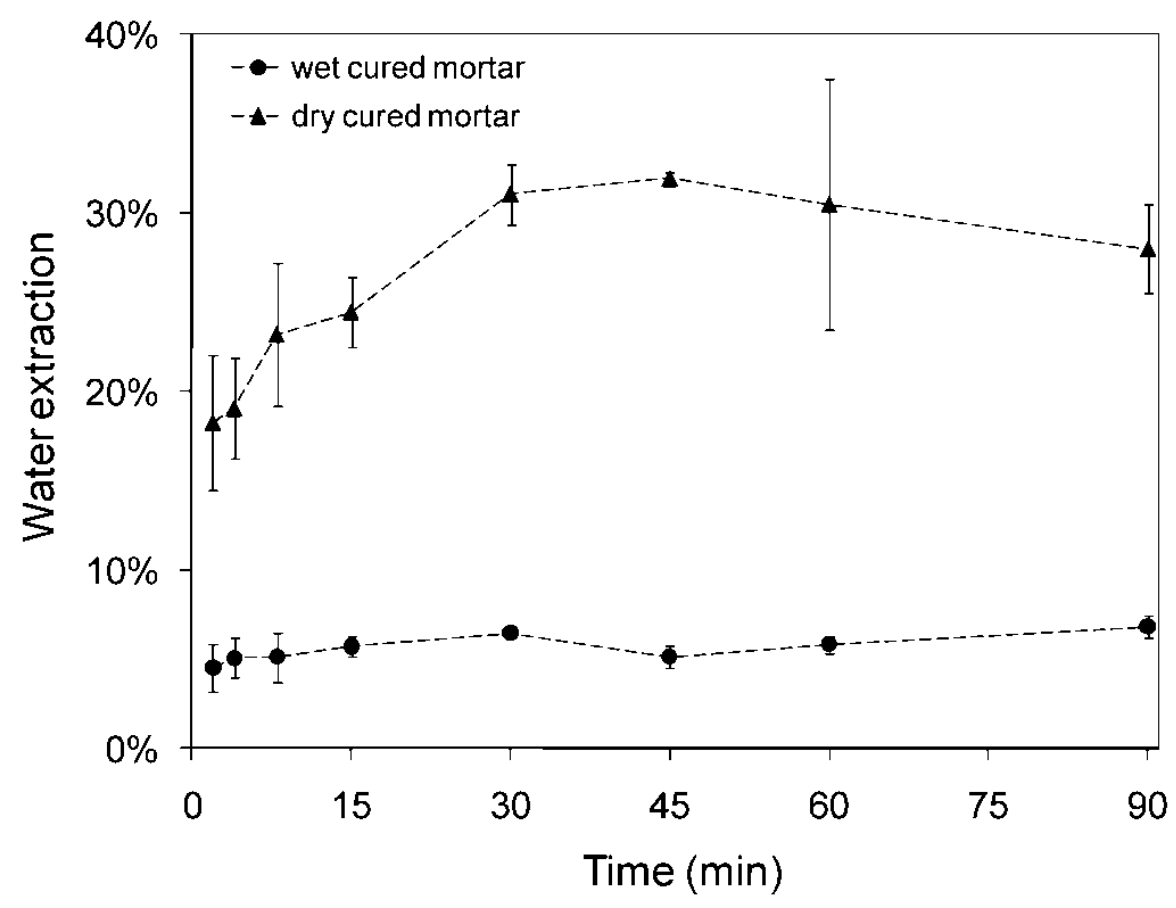

\section{Figure 14}

(a)

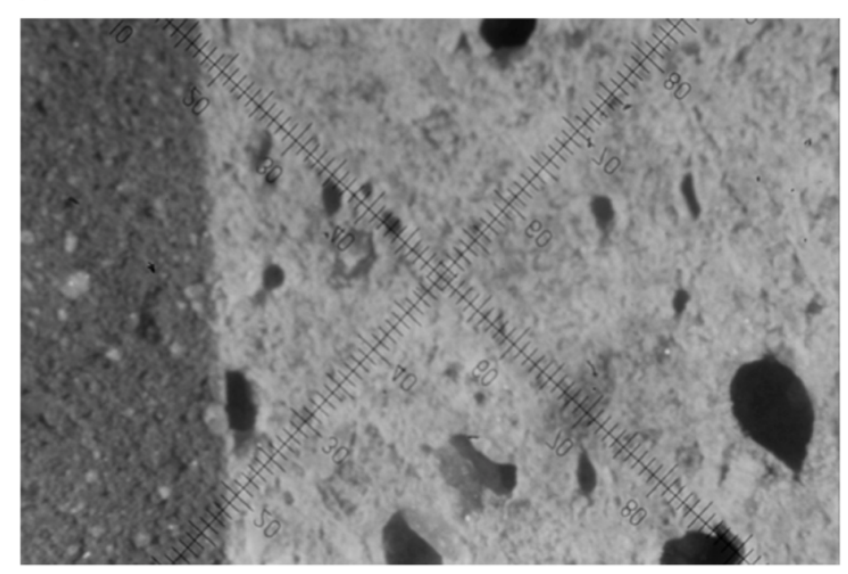

(b)

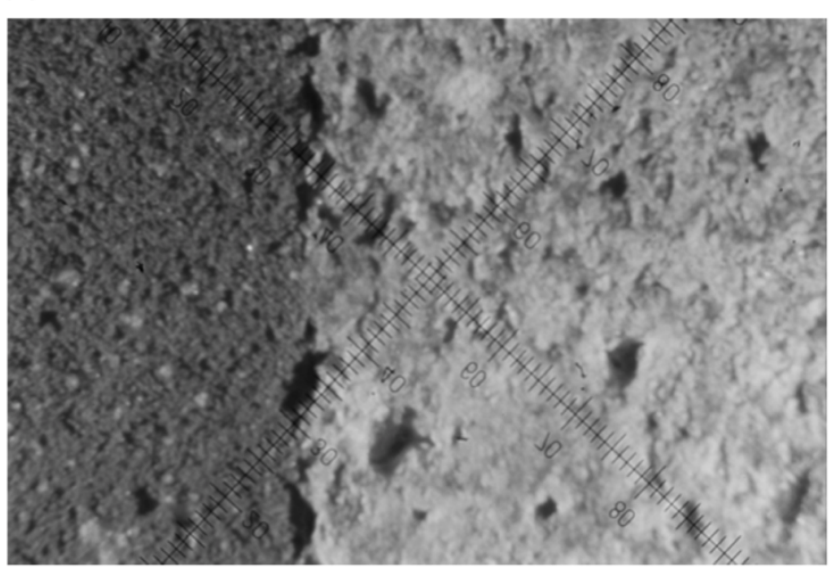

